\title{
Rainfall Infiltration under Various Building Layouts Using Concrete Microseepage Wells
}

\author{
Xiaolan Liu $(\mathbb{D}$, Shunqun Li, and Yunfeng Bai \\ Civil Engineering College, Tianjin Chengjian University, No. 26 Jinjing Road,Xiqing District, Tianjin 300384, China \\ Correspondence should be addressed to Xiaolan Liu; 1066323835@qq.com
}

Received 19 September 2021; Revised 27 January 2022; Accepted 7 February 2022; Published 25 February 2022

Academic Editor: Antonio Caggiano

Copyright ( $\odot 2022$ Xiaolan Liu et al. This is an open access article distributed under the Creative Commons Attribution License, which permits unrestricted use, distribution, and reproduction in any medium, provided the original work is properly cited.

\begin{abstract}
Low-impact development measures are a kind of ecological technology system that can easily realize urban rainwater collection and utilization to alleviate the contradiction between flooding/water logging disasters and water shortages. But most of the lowimpact development measures are difficult to solve the problem of deep soil infiltration and fully utilize runoff regulation and seepage benefits. Therefore, this paper proposes the concrete microseepage well with the optimum proportion of crushed stone, cement, and water of $1: 0.13: 0.11$ and $2 \%$ steel fiber content. The artificial rainfall experiment is applied to verify the highinfiltration of concrete microseepage well in deep soil. The numerical analysis shows that the concrete microseepage well around a single building and two adjacent buildings can all decrease $15 \%-40 \%$ of the pore water pressure, decrease $11 \%-33 \%$ of total head, and improve 43-55 times of infiltration velocity. The concrete microseepage well with $0.1 \mathrm{~m}$ in diameter and $1 \mathrm{~m}$ in height can affect the infiltration area of $1 \mathrm{~m}^{2}$. Each building being surrounded by seepage wells is the optimal layout scheme to alleviate the flooding/water logging disasters. This study provides a scientific reference for the development of sponge cities with low-impact development measures to reduce the problem of flooding/water logging disasters and water shortages.
\end{abstract}

\section{Introduction}

With increased urbanization, the contradiction between flooding/water logging disasters and water shortages is increasingly prominent. Hence, numerous management modes for handling flooding due to excess rainwater have been developed, such as Best Management Practices (BMPs), Low Impact Development (LID), Sustainable Urban Drainage System (SUDS), and Water Sensitive Urban Design (WSUD) $[1,2]$. Existing flood management measures, also called low-impact development measures, include permeable pavements, green roofs, sunken green spaces, planting ditches, seepage ditches, and seepage wells $[3,4]$. However, more basic flood management measures typically involve cement hardening, clay, silty clay, and other materials with poor infiltration, which makes it difficult to ensure effective rainwater infiltration and runoff regulation $[5,6]$. Thus, seepage wells have been adopted to improve existing flood management measures. Wang et al. [7] added a hollow pipe to a permeable concrete pavement structure in a weak-infiltration soil area and analyzed the runoff of the permeable concrete pavement structure under different rainfall conditions. Xu et al. [8] adopted steel gravel piles to carry out outdoor water injection tests on different types of permeable paving in low-infiltration soil areas and showed that the infiltration rate increased by $18-35$ times over that without steel gravel piles. Zhu et al. [9] used construction waste to form a seepage well and studied the water content of the soil layer under different spacings and depths of these wells. Their results proved that seepage wells effectively enhance the horizontal and vertical infiltration of the soil layer. Feng et al. [10] conducted in-situ infiltration tests and simulations with and without a grave seepage well and found that the infiltration flow was $67.12 \%$ higher with the seepage well. Liu et al. [11] carried out single-well and group-well infiltration tests in an area with predominantly clay soil and found that the grave seepage well was suitable for rainwater infiltration in such areas. Liang et al. [12] used numerical simulations and model tests to study the improved effect of seepage wells on infiltration and runoff control of a 
permeable grid under 72 rainfall conditions in Shijiazhuang, China.

Existing research has considered the use of various materials in rainwater seepage wells, making it difficult to determine exactly how the requirements of prefabricated buildings and green development can be satisfied. Moreover, existing research has tended to focus on the infiltration and runoff control of seepage wells to the original soil layer or permeable pavement, but there has been little research on the infiltration and runoff control of buildings around these seepage wells and pavement structures. Therefore, this paper describes the development of a green microseepage well that offers enhanced infiltration and durability over traditional concrete microseepage wells by changing the ratio of materials and the content of the steel fibers. The infiltration effect of the proposed concrete microseepage well under different rainfall intensities is verified through artificially simulated rainfall experiments. Moreover, numerical models of buildings and microseepage wells are verified by comparing the pore water pressure and infiltration velocity in the reference. And verified numerical models of buildings and microseepage wells are applied to analyze the pore water pressure, total head, and infiltration velocity with no seepage wells placed around buildings, seepage wells placed around a single building, and seepage wells placed around two adjacent buildings. Finally, the optimal layout scheme of concrete microseepage wells in the buildings is obtained based on the response of the pore water pressure, total head, and infiltration velocity. This research provides a scientific reference for the development of low-impact rainwater systems in so-called "sponge cities."

\section{Fabrication of Concrete Microseepage Wells}

Concrete microseepage wells were prefabricated using crushed stone, cement, water, and steel fibers, as shown in Tables 1-3. The concrete microseepage wells were formed by placing a filter layer of a certain thickness at the bottom of the seepage well holes, burying the preformed seepage wells in the seepage well holes, and filling the gap between the seepage wells and the seepage well holes with crushed stone, as shown in Figure 1.

Before producing the precast concrete microseepage wells, stones of different sizes were selected by stacking standard sieves, from large to small and top to bottom, and weighing the materials using an electronic spring balance with an accurate measuring range. The stone was mixed with cement by spades, and then the stone and cement were spread out from the middle by slowly adding water to prevent the cement slurry from sinking to the bottom. Steel fibers were evenly spaced in the mixture to ensure a full spread. A depth of about $0.1 \mathrm{~m}$ of the well-mixed concrete was added to the mold at a time, and a steel bar was used to hit the mold wall from top to bottom with high frequency until the concrete was no longer sinking. This process was repeated until the mold was full. After $12 \mathrm{~h}$ in a dark environment with a plastic bag tied tightly around the mold mouth, the concrete microseepage well was subjected to water injection at the mold mouth, and the well was maintained in the mold for 3 days. The mold was then carefully removed to avoid any local forces that may damage the well.

Based on many trials, the optimal mixture ratio of crushed stone, cement, and water was found to be $1: 0.13$ : 0.11 . Three types of concrete microseepage wells were made with $0.2-0.5 \mathrm{~cm}, 0.5-1.0 \mathrm{~cm}$, and $1.0-1.5 \mathrm{~cm}$ of crushed stone, respectively, and various amounts of steel fibers. To determine the best size of crushed stone and the optimal steel fiber content, infiltration, freeze-thaw, and compression tests were carried out.

2.1. Infiltration Test. Before the test, the concrete microseepage well with a diameter of $0.1 \mathrm{~m}$ and length of $0.5 \mathrm{~m}$ was coated with two layers of fresh-keeping film to avoid the influence of water seepage from the mold gap, as shown in Figure 2 . The seepage well was tightly wrapped with a $0.5 \mathrm{~m}$ long PVC pipe and locked with a throat collar. One end of the $0.5 \mathrm{~m}$-long PVC pipe was connected with the other end of a $1.0 \mathrm{~m}$-long PVC pipe. The joint was fixed with waterproof glue to prevent water leakage at the joint, thus forming an L-shaped penetration rate test device, as shown in Figure 3.

The L-shaped infiltration apparatus was placed vertically on the ground and connected to the tap through a water pipe. The tap was opened and water was injected into the $1.0 \mathrm{~m}$-long PVC pipe. When the water flow at the water outlet began to appear, the water was caught by the waterholding device. Meanwhile, the volume of water was calculated with measuring cylinders and the time began to be recorded with a stopwatch. The infiltration rate of each concrete microseepage well was obtained according to equation (1). The average values of the infiltration rates for three concrete microseepage wells were calculated and listed in Table 4.

$$
v=\frac{S}{t}
$$

where $v$ is the infiltration rate, $S$ is the infiltration volume, and $t$ is the infiltration time.

In Table 4, when the particle size of the crushed stone was $0.2-0.5 \mathrm{~cm}$, the mean infiltration rate was $0.055 \mathrm{~cm}^{3} / \mathrm{s}$. When the particle size of the crushed stone was $0.5-1.0 \mathrm{~cm}$, the mean infiltration rate was $0.223 \mathrm{~cm}^{3} / \mathrm{s}$. When the particle size of the crushed stone was $1.0-1.5 \mathrm{~cm}$, the mean infiltration rate was $0.670 \mathrm{~cm}^{3} / \mathrm{s}$. Hence, the infiltration rate of concrete microseepage wells increases as the particle size of the crushed stone increases. However, concrete microseepage wells are easily fractured in the course of construction with particle sizes of $1.0-1.5 \mathrm{~cm}$. Therefore, to ensure water infiltration and construction quality, the $0.5-1.0 \mathrm{~cm}$ crushed stone particle size was chosen to make the concrete microseepage wells.

2.2. Freeze-Thaw Test. Steel fiber contents of $0 \%, 1 \%, 2 \%$, and $4 \%$ were added to concrete microseepage well specimens with a height of $0.5 \mathrm{~m}$ and diameter of $0.1 \mathrm{~m}$. The specimens were divided into six groups according to the steel fiber 
Table 1: Material technical description of crushed stone.

\begin{tabular}{lcccc}
\hline Material technical description & Particle size $(\mathrm{cm})$ & Bulk density $\left(\mathrm{kg} / \mathrm{m}^{3}\right)$ & Volume void ratio (\%) & Mud content $(\%)$ \\
\hline Crushed stone & $0.2-1.5$ & 2640 & 41.5 & 0.6 \\
\hline
\end{tabular}

TABLE 2: Material technical description of cement.

\begin{tabular}{lllll}
\hline Material technical description Ignition loss (\%) & Specific surface area $\left(\mathrm{m}^{2} / \mathrm{kg}\right)$ & Compressive strength $(\mathrm{MPa})$ & Flexural strength $(\mathrm{MPa})$ \\
\hline
\end{tabular}

\begin{tabular}{lllll}
\hline Cement (PO42.5) & 3.6 & 390 & 42.5 & 6.7
\end{tabular}

TABLE 3: Material technical description of steel fiber.

\begin{tabular}{lcccc}
\hline Material technical description & Bulk density $\left(\mathrm{kg} / \mathrm{m}^{3}\right)$ & Length $(\mathrm{cm})$ & Width $(\mathrm{cm})$ & Tensile strength $(\mathrm{MPa})$ \\
\hline Steel fiber (wavy) & 7000 & 3.6 & 0.3 & 500 \\
\hline
\end{tabular}

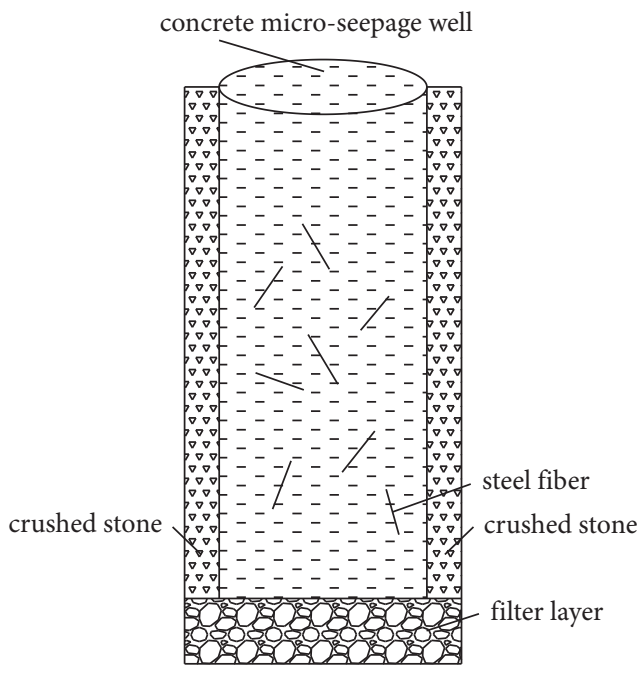

FIgURE 1: Schematic representation of a concrete microseepage well.

content, and each group was subjected to either $0,30,60,90$, 120, or 150 freeze-thaw cycles. A freeze-thaw chamber was used for these tests. The freeze-thaw time was $24 \mathrm{~h}$.

Before the test, the specimens were taken out of the curing box after 2 days. Then, the specimens were soaked in water at $15-20^{\circ} \mathrm{C}$ for 2 days and the water on the surface of the specimen was removed. The specimens after treatment were weighed and numbered in groups. Finally, the specimens were placed in the freeze-thaw chamber (Figure 4) and the test started. The freeze-thaw process was as follows: the specimens were placed in the freeze-thaw chamber when the temperature reached $-20^{\circ} \mathrm{C}$. Each freezing and thawing stage lasted $12 \mathrm{~h}$, with one freezing event and one thawing event defined as a freeze-thaw cycle. To ensure a consistent water content in the specimens during the freeze-thaw test, the specimen was placed back into the water tank at $15-20^{\circ} \mathrm{C}$ for 2 days after each freeze-thaw cycle, and then the water on the surface of the specimen was removed and the next freeze-thaw cycle started. The above freeze-thaw process was repeated until the number of freeze-thaw cycles had been completed (reach 0 , $30,60,90,120$, or 150 freeze-thaw cycles) or the specimen was damaged. During the freeze-thaw process, a visual inspection of the specimen was conducted and the quality of the specimen was measured and recorded every 30 freeze-thaw

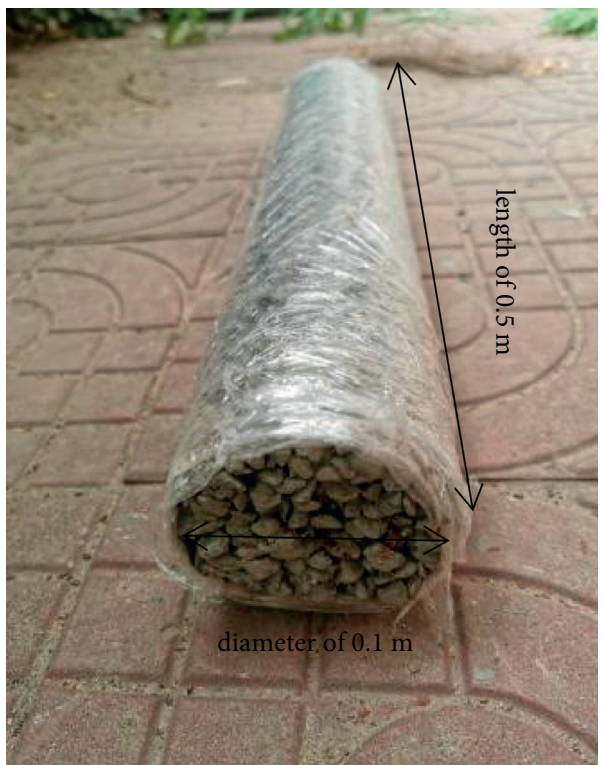

Figure 2: Seepage well wrapped in plastic film.

cycles. The mass-loss rate of each specimen at every 30 freezethaw cycles was calculated according to equation (2). The results are shown in Figure 5.

$$
\Delta m_{n}=\frac{m-m_{n}}{m}
$$

where $\Delta m_{n}$ is the mass loss rate after $n$ freeze-thaw cycles, $m$ is the specimen mass before the freeze-thaw cycles, and $m_{n}$ is the specimen mass after $n$ freeze-thaw cycles.

Figure 5 shows that the mass loss rate of the specimen without any steel fibers is $0.45 \%$ after 120 cycles of freezing and thawing, compared with mass loss rates of $0.38 \%, 0.31 \%$, and $0.25 \%$ for the specimens with $1 \%, 2 \%$ and $4 \%$ steel fiber contents. After 150 freeze-thaw cycles, the mass loss rate of the specimen with $1 \%$ steel fibers is $0.45 \%$, but the specimens with $2 \%$ and $4 \%$ steel fibers still have mass loss rates of less than $0.4 \%$. Because some microcracks appear in the specimens after relatively few freeze-thaw cycles, the addition of steel fibers has little effect on the mass loss of the specimens in the early stages. As the number of freeze-thaw cycles increases, the microcracks expand, and the specimens start to be destroyed, increasing the mass loss. Therefore, the incorporation of steel fibers effectively 


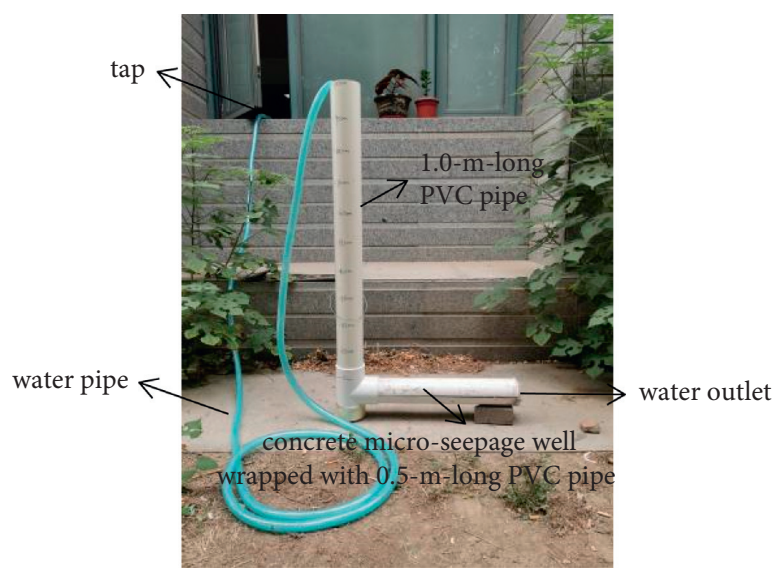

FIGURE 3: L-shaped infiltration apparatus.

TABLE 4: Infiltration rates.

\begin{tabular}{lccccc}
\hline Particle size $(\mathrm{cm})$ & Code & $t(\mathrm{~s})$ & $S\left(\mathrm{~cm}^{3}\right)$ & $v\left(\mathrm{~cm}^{3} / \mathrm{s}\right)$ & Mean infiltration $\mathrm{rate}^{3}\left(\mathrm{~cm}^{3} / \mathrm{s}\right)$ \\
\hline \multirow{3}{*}{$0.2-0.5$} & 1 & 230 & 13.5 & 0.059 & 0.055 \\
& 2 & 235 & 12.8 & 0.053 & 0.055 \\
$0.5-1.0$ & 3 & 220 & 11.6 & 0.234 & 0.223 \\
& 1 & 137 & 32.1 & 0.230 & 0.670 \\
\hline \multirow{3}{*}{$1.0-1.5$} & 2 & 130 & 26.8 & 0.688 & 0.683 \\
& 3 & 126 & 29.0 & 0.640 & \\
\hline
\end{tabular}

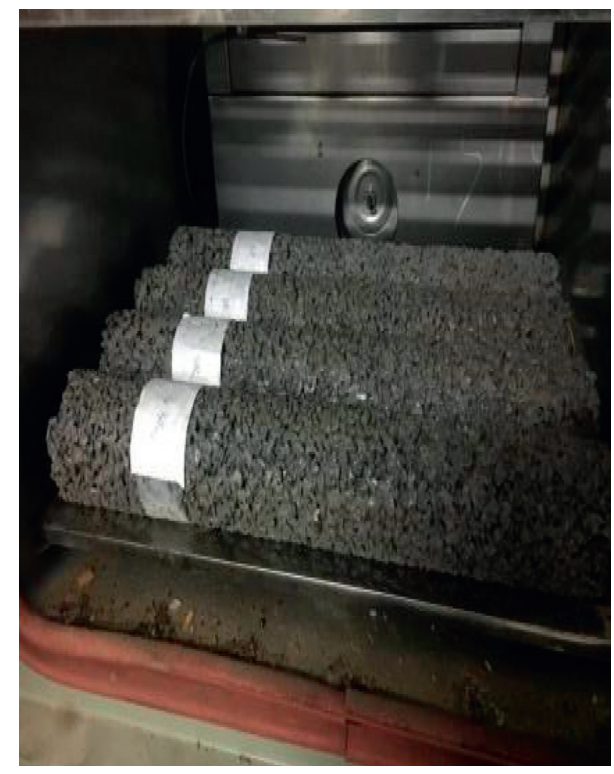

Figure 4: Specimens in the freeze-thaw chamber.

restrains the formation and development of fractures in the seepage well and reduces the erosion of the seepage well caused by freeze-thaw cycles.

2.3. Compression Test. After the freeze-thaw cycle test, six groups of freeze-thaw specimens were subjected to compression tests according to the specification of soil test done

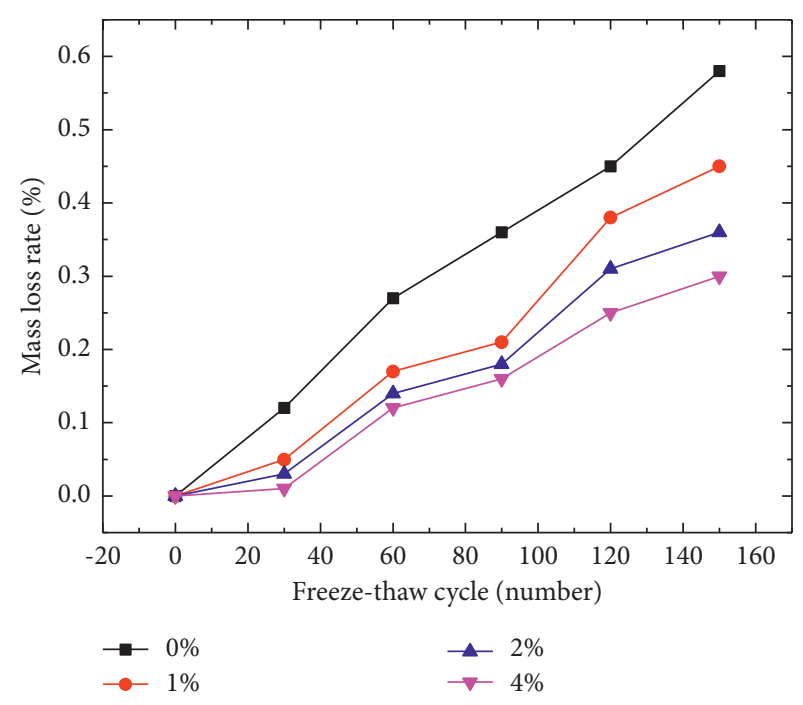

Figure 5: Mass loss rate in the freeze-thaw test.

in CIMRS (Changchun Research Institute for Mechanical Science Co., Ltd.) Brand compression testing machine with the maximum axial load of $20 \mathrm{kN}$. The specimens were subjected to continuous and uniform loading at speeds ranging from 6 to $10 \mathrm{kN} / \mathrm{s}$. The damaged specimen is shown in Figure 6. When the specimen became damaged, the compression-testing machine automatically stopped loading. The compressive strengths of the specimens with different steel fiber contents are shown in Figure 7. 


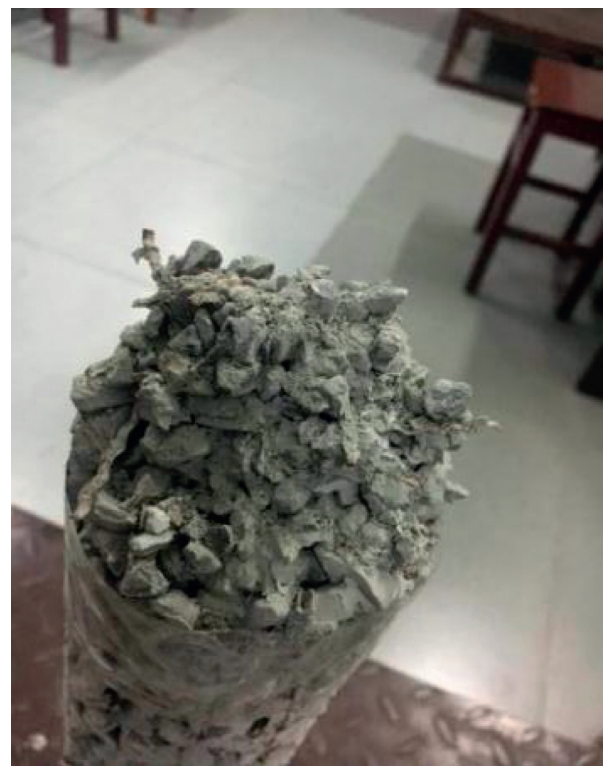

FIgURE 6: The damaged specimen in the compression test.

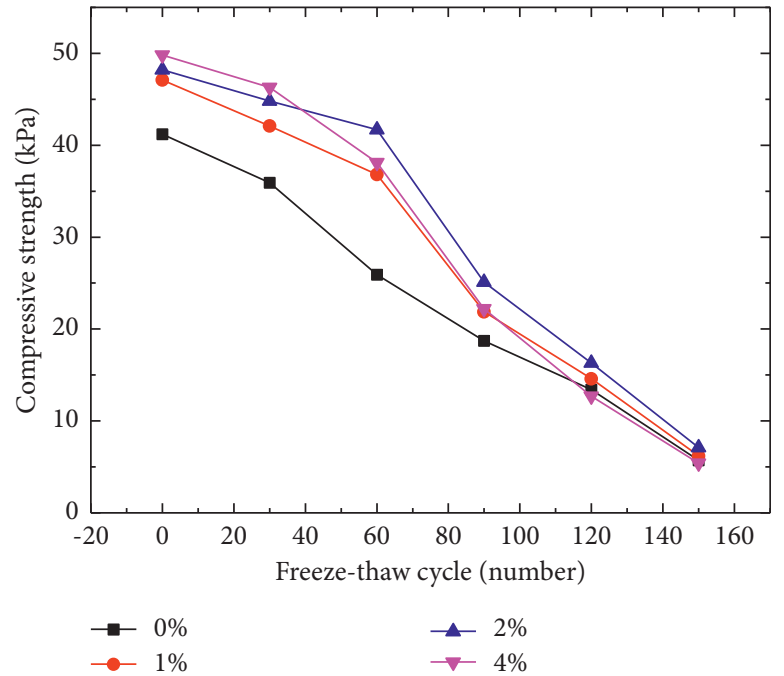

(a)

Figure 7: The compressive strength of specimens after (a) 0-150 freeze-thaw cycles and (b) 90-150 freeze-thaw cycles.

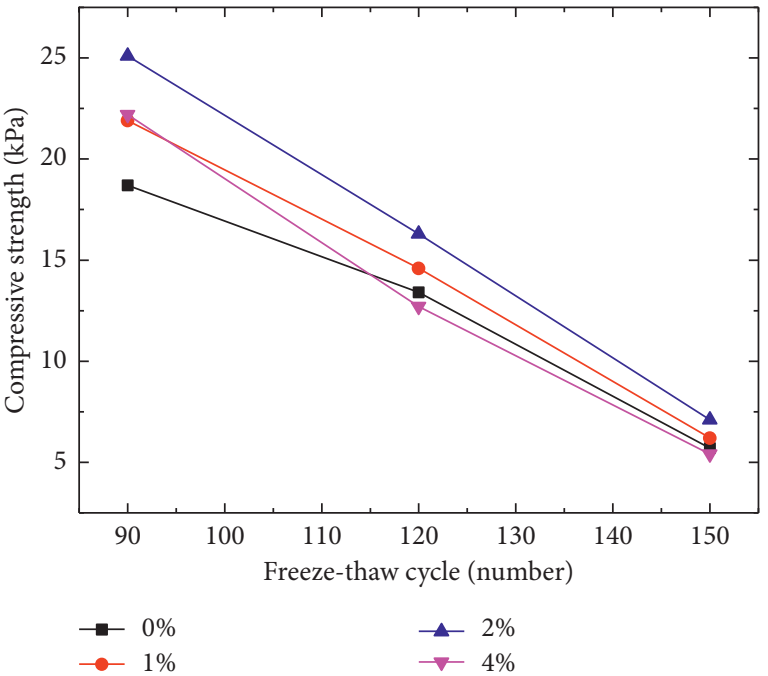

(b)
As shown in Figure 7, when the number of freeze-thaw cycles is less than 60 , the compressive strengths of 8 specimens (The specimens are with the steel fiber contents of $0 \%$ at 0 and 30 freeze-thaw cycles, the steel fiber contents of $1 \%$ at 0 and 30 freeze-thaw cycles, the steel fiber contents of $2 \%$ at 0 and 30 freeze-thaw cycles, and the steel fiber contents of $4 \%$ at 0 and 30 freeze-thaw cycles.) decrease with the increase of freeze-thaw cycles and increase with the growth of the steel fiber content. However, when the number of freeze-thaw cycles is more than 60 , the differences in compressive strengths of 16 specimens decrease gradually and the specimen with $2 \%$ steel fibers has the highest compressive strength. After 120 freezethaw cycles, the compressive strength of the specimen with $4 \%$ steel fibers is $1.9 \%$ less than that of the specimen without any steel fibers; after 150 freeze-thaw cycles, the specimen with $4 \%$ steel fibers has a compressive strength that is $6.5 \%$ lower than that of the specimen without any steel fibers.

The compressive strength of the specimens clearly decreases as the number of freeze-thaw cycles increases. When the steel fiber content is no greater than $2 \%$, the compressive strength of specimens after the same number of freeze-thaw cycles increases with the steel fiber content. The sample with $4 \%$ steel fibers has the highest compressive strength after 30 freeze-thaw cycles, but this decreases gradually as the number of freeze-thaw cycles increases, and the degradation becomes more obvious when the number of freeze-thaw cycles reaches 150 . At higher steel fiber content, there is a reduction in compressive strength which may be due to the balling of steel fibers as reported by other researchers [13-15]. 


\section{Outdoor Test of Concrete Microseepage Well}

Artificially simulated rainfall experiments were used to analyze the variations in surface water accumulation and soil moisture content of the concrete microseepage well under different rainfall intensities. The effect of the concrete microseepage well on improving soil infiltration was also explored.

3.1. Test Scheme. The test site was the South Garden of the Tianjin Chengjian University stadium. The test site was cleared and leveled before the test. According to the test scheme with observation points (Figure 8(a)), a Luoyang shovel was used to dig seepage well holes with a diameter slightly greater than $0.1 \mathrm{~m}$ and a depth slightly greater than $1.0 \mathrm{~m}$ at test site I. Soil samples were taken at depths of $0.2 \mathrm{~m}$, $0.4 \mathrm{~m}, 0.6 \mathrm{~m}, 0.8 \mathrm{~m}$, and $1.0 \mathrm{~m}$, and the water content of the soil at these depths was measured. A concrete microseepage well with a diameter of $0.1 \mathrm{~m}$ and a height of $1.0 \mathrm{~m}$ was then embedded in the seepage well hole. An adjacent $3 \mathrm{~m} \times 3 \mathrm{~m}$ area (test site II) was used as the contrast site. To prevent the rain outflow from influencing the test results, the test site was surrounded by a graduated water retaining plate, the four corners of which were sealed with waterproof glue after the seepage well had been buried.

As shown in Figure 8(b), the height of the NLJY-10 artificial simulated rainfall system was set to $4 \mathrm{~m}$ according to the scope of the test site. Pipe tongs were used to connect 14 rain pipes in order to form a pipe control system. The controller, press machine, and generator were connected in turn to form a rain control system. The pipeline control system, rainfall control system, and water tank were connected by water pipes to form the artificial rainfall simulation equipment. The water tank (capacity $1000 \mathrm{~L}$ ) was filled with water, and the generator and press were switched on, whereby the rain intensity could be adjusted by the controller. The "sweeping and spraying" rainfall method was adopted to extend the rainfall time as far as possible and to simulate light, moderate, heavy, and rainstorm conditions more realistically.

3.2. Results Analysis. Considering the typical summer rainfall situation in Tianjin, moderate, heavy, and rainstorm intensities were set to $0.03 \mathrm{~m} / \mathrm{h}, 0.06 \mathrm{~m} / \mathrm{h}$, and $0.09 \mathrm{~m} / \mathrm{h}$, respectively; the rainfall duration was set to $2 \mathrm{~h}$. The volume of impounded surface water was recorded at 5 min intervals after the rainfall had finished (Figure 9), and soil samples were taken using the Luoyang shovel to test the water content after the surface water had fully infiltrated the well (Figure 10). The water retaining plate was graduated. The volume of the surface water was obtained by multiplying the area of the test site and the surface water height from the graduated water retaining plate.

As shown in Figure 9, the surface water accumulation gradually decreases after the rainfall has stopped. At test site $\mathrm{I}$, the time history curve of $0.03 \mathrm{~m} / \mathrm{h}$-I shows that there is no surface water after the rainfall has finished for $20 \mathrm{~min}$. The time history curves of $0.06 \mathrm{~m} / \mathrm{h}-\mathrm{I}$ and $0.09 \mathrm{~m} / \mathrm{h}-\mathrm{I}$ show that the surface water disappears after the rainfall has finished for $30 \mathrm{~min}$. At test site II, the time history curve of $0.09 \mathrm{~m} / \mathrm{h}$-II shows that $0.17 \mathrm{~m}$ of surface water remains after the rainfall has finished for $30 \mathrm{~min}$, and it takes $55 \mathrm{~min}$ for the surface water to reach a level of zero. When the rainfall intensity is $0.09 \mathrm{~m} / \mathrm{h}$, the reduction in the surface water level and the time required to reach zero surface water are faster at site I (the time history curve of $0.09 \mathrm{~m} / \mathrm{h}-\mathrm{I}$ ) than at site II (the time history curve of $0.09 \mathrm{~m} / \mathrm{h}$-II). At test site I, the surface water curve is relatively smooth when the rainfall intensity is $0.03 \mathrm{~m} / \mathrm{h}$ and $0.06 \mathrm{~m} / \mathrm{h}$, but the change in surface water level is significant when the rainfall intensity is $0.09 \mathrm{~m} / \mathrm{h}$. When the rainfall intensity is low, the surface water mainly penetrates through the surface soil, and only a small part penetrates through the infiltration well. A greater volume of surface water accumulates under the rainstorm intensity, and the soil water content increases and gradually reaches the saturation condition. Most of the surface water then infiltrates through the seepage well, thus speeding up the rainwater infiltration and enhancing the infiltration rate. These results show that the seepage well arrangement can enhance the infiltration effect of the soil and reduce the surface water accumulation caused by short-duration heavy rainfall.

As can be seen from Figure 10, the water content at each observation point decreases as the distance between seepage wells increases. Observation points 1 and 3, 4 and 8,9 and 11, and 12 and 16 have similar and higher water contents than other observation points in the same group. The water content at observation points 2 and 10 changes little at depths of $0.2 \mathrm{~m}, 0.4 \mathrm{~m}$, and $0.6 \mathrm{~m}$, but clearly decreases at depths of $0.8 \mathrm{~m}$ and $1.0 \mathrm{~m}$. The water content of observation point 2 at a depth of $1.0 \mathrm{~m}$ is higher than that at a depth of $0.8 \mathrm{~m}$. The water content of observation points 6 and 14 obviously decreases at depths of $0.2 \mathrm{~m}, 0.4 \mathrm{~m}$, and $0.6 \mathrm{~m}$ but changes little at depths of $0.8 \mathrm{~m}$ and $1.0 \mathrm{~m}$. Moreover, the variation in water content at the same horizontal distance is basically consistent. Therefore, the soil water content decreases with increasing depth at the same horizontal distance and decreases with increasing horizontal distance at the same depth. The spacing of the seepage wells has a definite influence on the infiltration of rainwater. A smaller spacing results in smaller variations in soil water content between seepage wells.

These results can be explained as follows. The water content in the soil increases with rainfall infiltration, and the pore water pressure reduces the infiltration rate of surface water. At the same time, the infiltration coefficient of the seepage well is much larger than that of the surrounding soil. Most of the surface water permeates through the seepage well and diffuses rapidly to the surrounding soil, and the water content in shallow soil increases significantly. In addition, the water head decreases as water diffuses to the surrounding soil, so the water content decreases with increasing horizontal distance. In the process of rainwater infiltration, there may be interference between the seepage wells if the spacing is too small. The infiltration capacity of the loose and soft shallow soil is strongly affected by two seepage wells, and so the soil tends to become saturated. The 


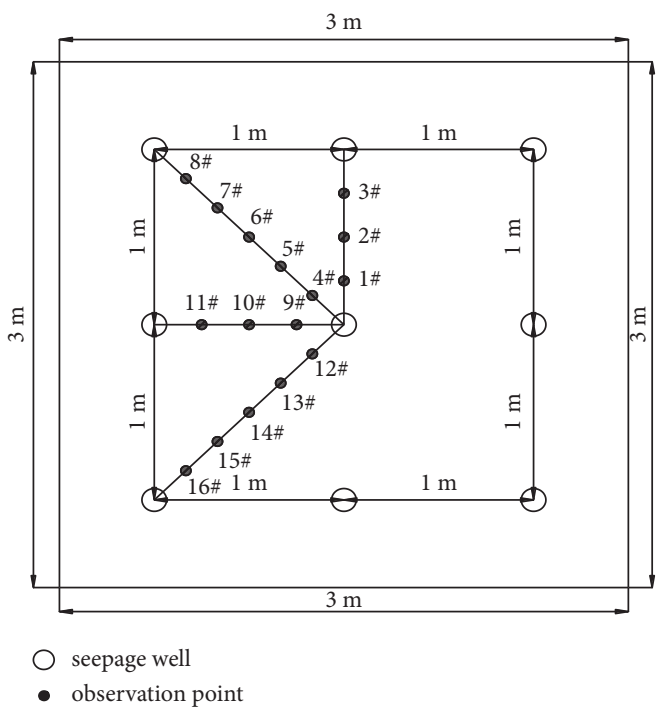

(a)

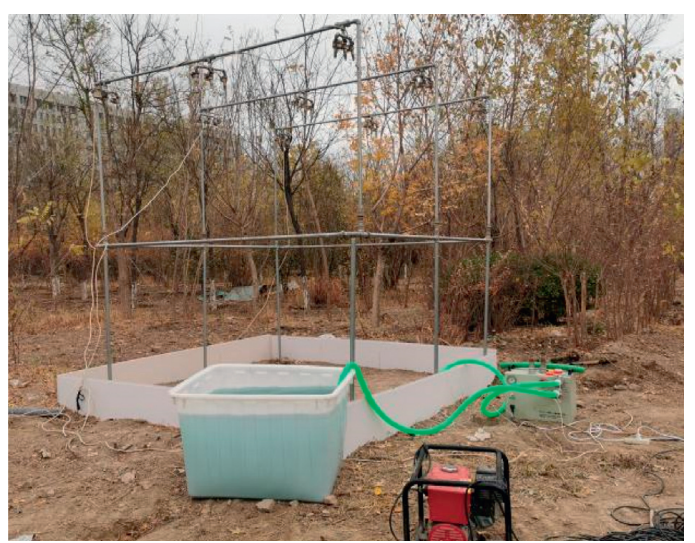

(b)

FIGURE 8: Scheme of test site I with (a) observation points and (b) artificial simulated rainfall system (observation points are set located at equal intervals).

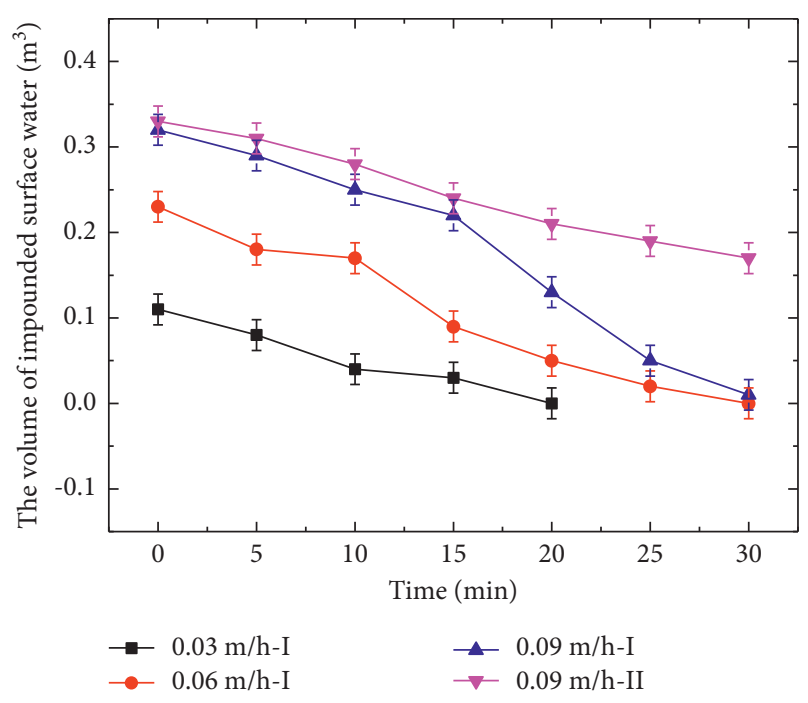

FIGURE 9: Time history curve of impounded surface water in the artificially simulated rainfall experiment (the time of $0 \mathrm{~min}$ is to indicate that the rainfall has just stopped. When there is no impounded surface water, the volume of impounded surface water is $0 \mathrm{~m}^{3}$. The error bar means the root mean square error of the volume of impounded surface water.).

water content of the loose and soft shallow soil decreases as the depth increases, but this trend is not obvious. Test results show that the water content increases slightly at the same horizontal distance and decreases with increasing depth. When the distance between the seepage wells is large, there is a nonseepage well action zone in the middle of two seepage wells. The results show that the water content of the observation points decreases significantly at first and then increases at the same horizontal distance. Therefore, the concrete microseepage wells can improve the infiltration and increase the infiltration rate of in-situ soil. However, the optimum spacing of the concrete microseepage wells should be determined according to the site area and seepage requirements so as to satisfy the site function requirements and avoid material waste.

\section{Model of Concrete Micro-Seepage Wells around Buildings}

To explore the optimal spacing of concrete microseepage wells in the buildings, a numerical model was established by means of finite element software to analyze the influence of four seepage wells schemes on rainfall infiltration. The response laws of the pore water pressure, total head, and infiltration velocity are discussed, and the best seepage well scheme for a group of buildings is identified.

4.1. Infiltration Theory. When water enters the soil skeleton, it flows along with the void under the action of potential energy difference, which is the infiltration phenomenon in the soil. Because the pore passage of soil is small and tortuous, the viscous resistance of the fluid tends to be very large and the flow velocity tends to be slow. Thus, it is difficult to penetrate downward, and the fluid is mostly in the laminar flow state. Darcy carried out a large number of experiments to determine the law governing the velocity of water flow and the water head in the soil in the state of laminar flow, eventually deriving the three-dimensional seepage differential equation of heterogeneous soils [16]:

$$
\frac{\partial}{\partial x} k_{x} \frac{\partial h}{\partial x}+\frac{\partial}{\partial y} k_{y} \frac{\partial h}{\partial y}+\frac{\partial}{\partial z} k_{z} \frac{\partial h}{\partial z}=\mu_{s} \frac{\partial h}{\partial t},
$$

where $k_{x}, k_{y}$, and $k_{z}$ are infiltration coefficients of soil on the $X, Y$, and $Z$ coordinate axis. $h$ is the water head. $\mu_{s}$ is the unit water storage capacity, and $\mu_{s}$ is equal to $\rho g\left(E_{s}+\eta E_{w}\right) . \rho$ is the density. $g$ is the gravitational acceleration. $E_{s}$ is the 


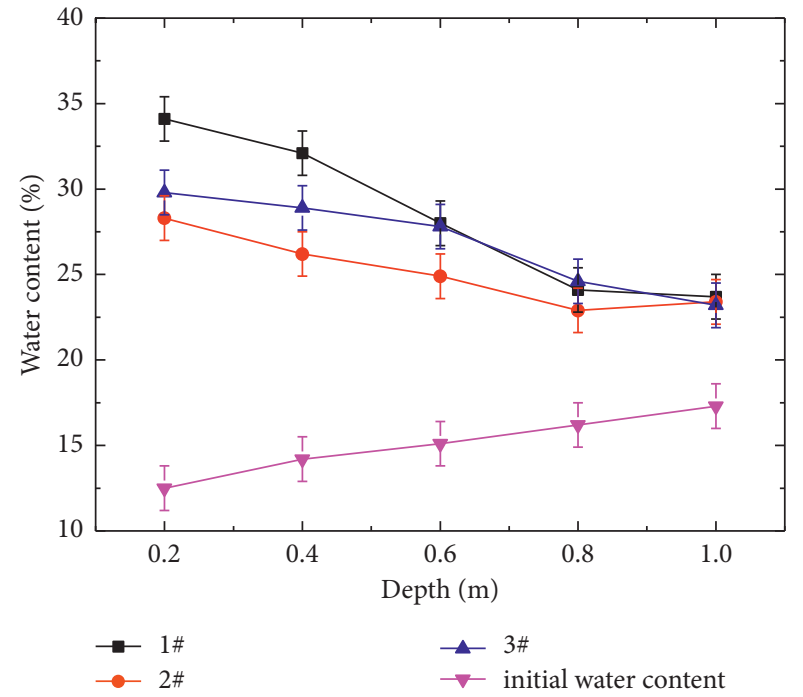

(a)

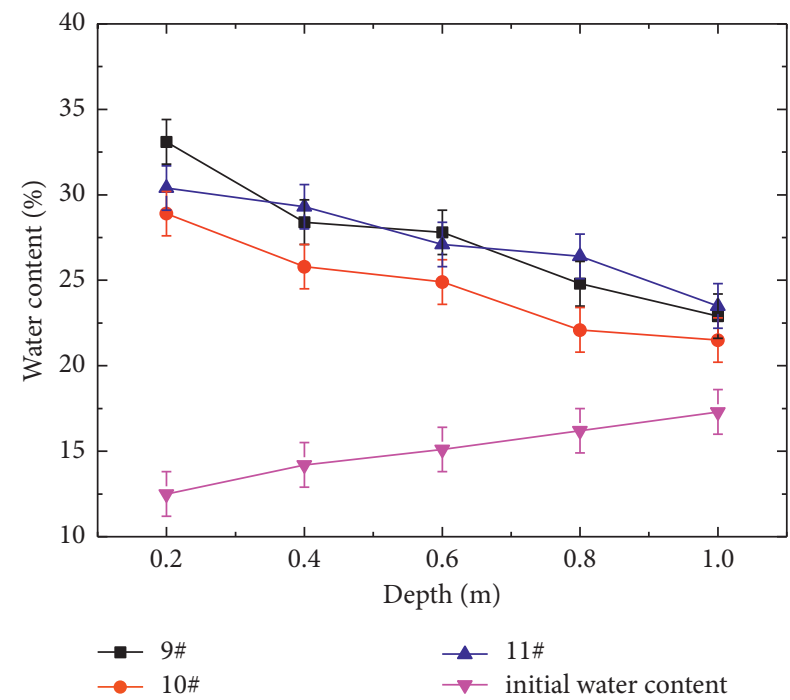

(c)

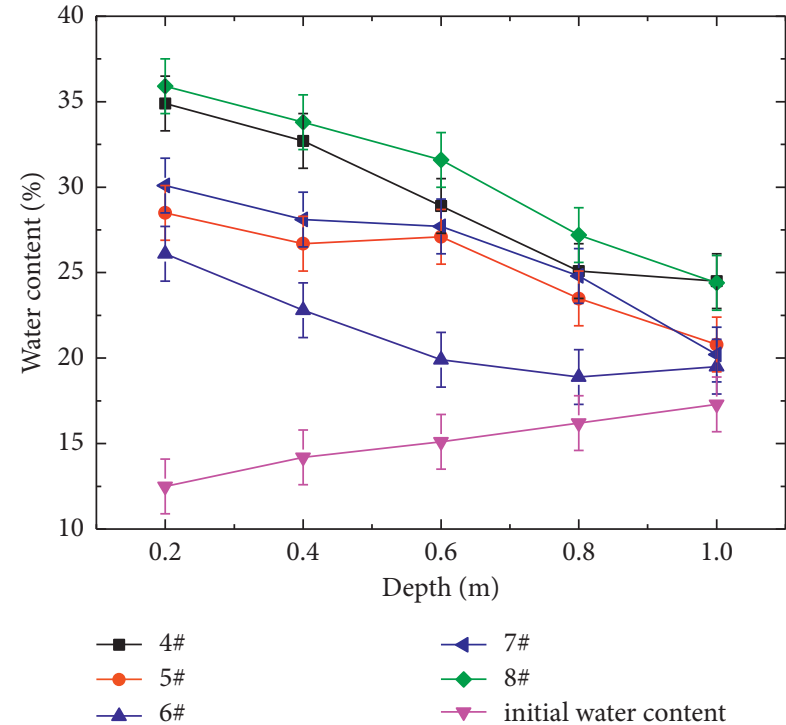

(b)

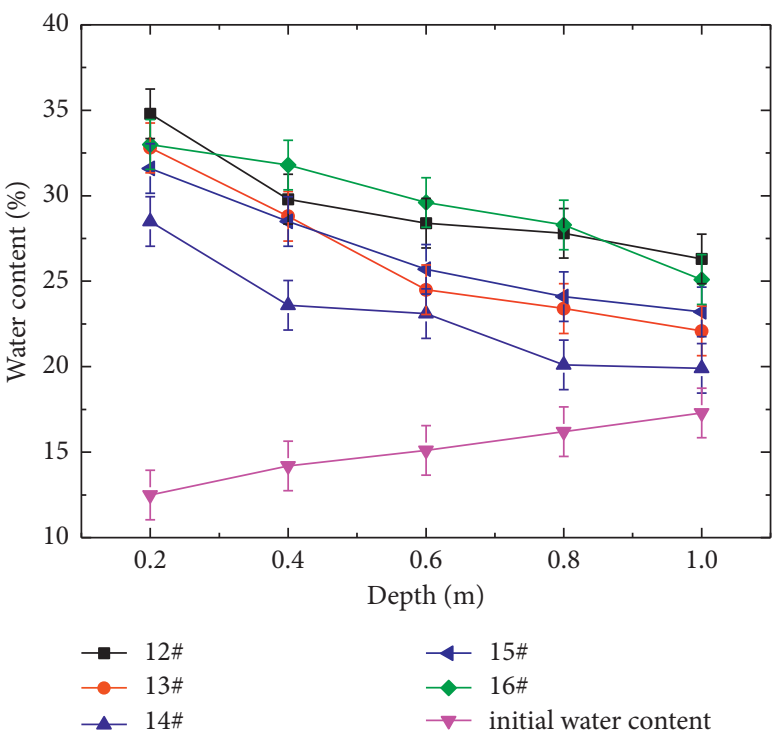

(d)

FiguRE 10: Water content at observation points (a) 1-3, (b) 4-8, (c) 9-11, and (d) 12-16 in the artificially simulated rainfall experiment (the error bar means the root mean square error of the water content.).

compression modulus of soil. $\eta$ is the void ratio of soil. $E_{w}$ is the compression modulus of water.

For the isotropic seepage field, $k_{x}, k_{y}$, and $k_{z}$ are assumed to $k$. The three-dimensional seepage differential equation can be shown as follows:

$$
\frac{\partial^{2} h}{\partial x^{2}}+\frac{\partial^{2} h}{\partial y^{2}}+\frac{\partial^{2} h}{\partial z^{2}}=\frac{\mu_{s}}{k} \frac{\partial h}{\partial t}
$$

The initial conditions for infiltration are generally shown as follows [17]:

$$
\left.h\right|_{t=0}=f_{0}(x, y, z, t) .
$$

The boundary conditions for infiltration are generally of the following three types $[18,19]$ :
For the first type of boundary conditions, $\Gamma_{1}$ is the boundary of the infiltration region. The water head is known at any time and can be directly assigned on the boundary according to the following:

$$
\frac{h}{\Gamma_{1}}=h_{1}(x, y, z, t) .
$$

This type of boundary condition should not be used to define a certain boundary as a constant head boundary without a complete basis or clear conditions.

For the second type of boundary condition, $\Gamma_{2}$ is a boundary with a given inflow or its own water level. $\Gamma_{2}$ is a flow line for steady infiltration, and satisfies the following formula in the case of unsteady infiltration: 


$$
\frac{-k \partial h / \partial n}{\Gamma_{2}}=q_{1}(x, y, z, t),
$$

where $n$ is the normal direction to the boundary and $q_{1}$ is the unit width on $\Gamma_{2}$.

$\Gamma_{3}$ is the boundary of the infiltration curve of the previous weak layer and satisfies the following:

$$
H+\alpha H=n \beta,
$$

where $\mathrm{a}$ and $\beta$ are known functions.

The hydraulic characteristics of unsaturated soil are described by the function of Van Genuchten [20].

$$
\begin{aligned}
& \theta(h)= \begin{cases}\theta_{r}+\frac{\theta_{s}-\theta_{r}}{\left[1+|a h|^{b}\right]^{m}}, & (h<0), \\
\theta_{s}, & (h \geq 0),\end{cases} \\
& K(h)=K_{s} S_{e}^{l}\left[1-\left(1-S_{e}^{1 / m}\right)^{m}\right]^{2},
\end{aligned}
$$

where $\theta(h)$ and $K(h)$ are the water retention function of soil and the infiltration function. $\theta_{r}$ and $\theta_{s}$ are the residual water content and the saturation water content. $a$ is the bubble pressure. $b$ is the distribution index of pore diameter. $m$ is the empirical coefficient. $K_{s}$ is the saturation infiltration coefficient. $S_{e}$ is the effective moisture content of soil. $l$ is the pore connectivity parameter.

4.2. Model Establishment. It is assumed that (1) The soil mass is isotropic and continuous, and the deformation of the soil is small and can be neglected. (2) The fluid movement of the water flow conforms to the three-dimensional seepage differential equation (4). (3) Poisson's ratio and the infiltration coefficient of the soil are both constant. (4) The stress effect of rainfall on the soil is not considered during rainfall events (Table 3 ). (5) The building is simplified to a $0.3 \mathrm{~m}$ thick impervious layer. Numerical models of buildings and microseepage wells are established based on the three-dimensional seepage differential equation (4). The initial condition and boundary condition of building and microseepage well numerical models are determined by equations (5) and (6), respectively. The whole numerical model of building and microseepage well is meshed in the method of hybrid grid generators. The three-dimensional hexahedron element is used to mesh the numerical model of building and microseepage well. The whole numerical model of building and microseepage well includes 267245 nodes and 553210 elements. The three-dimensional mesh model of building is shown in Figure 11.

The left-right boundary, the front-back boundary, and the lower boundary of numerical models are all impermeable. The upper boundary of the numerical model is set by a curved flux of $0.06 \mathrm{~m} / \mathrm{h}$ rainfall rate [20]. The left-right boundary of the numerical model constraints $X$-direction displacement. The front-back boundary of the numerical model constraints $Z$-direction displacement. The lower boundary of the numerical model constraints all displacement. The Mohr-Cullen model is used to simulate the constitutive relation of soil in the infiltration analysis. To consider the hydraulic characteristics of unsaturated soil, the function of Van Genuchten (equations (9) and (10)) is adopted. The initial water head is set at $3 \mathrm{~m}$ away from the surface of the pavement.

The seepage wells measure $0.1 \mathrm{~m}$ in diameter and $1 \mathrm{~m}$ in height and are spaced at 1-m intervals. The infiltration stage is divided into two stages. The initial stage is the steady-state and reflects the initial water head. The second stage is transient and covers a time period of $2 \mathrm{~h}$, divided into 12 steps of $10 \mathrm{~min}$. The unsaturated influence is considered, but the maximum value of the negative pore pressure is neglected in the model.

The numerical model includes $1.1 \mathrm{~m}$ of plain fill soil and $3.9 \mathrm{~m}$ of clay. The soil parameters are listed in Table 5 [21]. The buildings are shown in Figure 12, a schematic diagram of the pavement structure is shown in Figure 13, and the parameters of the pavement structures are presented in Table 6 [16]. A single building and the surrounding roads with a series of seepage wells installed are shown in Figure 14. Three observation points are selected on the surface of the plain fill soil, and the distance between observation points and adjacent seepage wells is $0.25 \mathrm{~m}$.

4.3. Results and Discussion. Based on the numerical model described above, the influence of four seepage wells schemes on the rainfall infiltration around the four buildings is now analyzed. The indexes of pore water pressure, total head, and infiltration velocity are discussed.

\subsubsection{Without Seepage Wells}

(1) Pore Water Pressure. The pore water pressure nephograms following $10 \mathrm{~min}$ and $120 \mathrm{~min}$ of rainfall are shown in Figure 15. These nephograms reflect the changes in the whole pore water pressure of the buildings without any seepage wells.

The change in the pore water pressure over $120 \mathrm{~min}$ of rainfall is analyzed at observation points 1-3 in Figure 16.

Figures 15 and 16 show that the pore water pressure of the four buildings is symmetrical without any seepage wells, and the pore water pressure at the corresponding positions is the same. When the rainfall time is $10 \mathrm{~min}$, the pore water pressures at observation points 1 and 3 are $-3.844 \mathrm{kN} / \mathrm{m}^{2}$ and $-5.442 \mathrm{kN} / \mathrm{m}^{2}$, respectively, which are similar to $-4.451 \mathrm{kN} / \mathrm{m}^{2}$ in the study of Hou et al. [21]. In the study of Hou et al. [21], the site of the in-situ infiltration test is located in the Hai River Education Park, Jinnan District Nankai University, Tianjin. The site is $3 \mathrm{~m} \times 3 \mathrm{~m}$ area and includes $1.1 \mathrm{~m}$ of plain fill soil and $3.9 \mathrm{~m}$ of clay. The rainfall intensity is $0.058 \mathrm{~m} / \mathrm{h}$. The pore water pressure of $-4.451 \mathrm{kN} / \mathrm{m}^{2}$ is obtained at the middle of the site. When the rainfall time is $20 \mathrm{~min}$, the pore water pressures at observation points 1-3 are $-0.786 \mathrm{kN} / \mathrm{m}^{2},-1.565 \mathrm{kN} / \mathrm{m}^{2}$, and $-0.747 \mathrm{kN} / \mathrm{m}^{2}$, respectively. As the rainfall time increases from $20 \mathrm{~min}$ to $120 \mathrm{~min}$, the pore water pressures of observation points 1 and 3 tend to be stable and are similar. As the rainfall time 


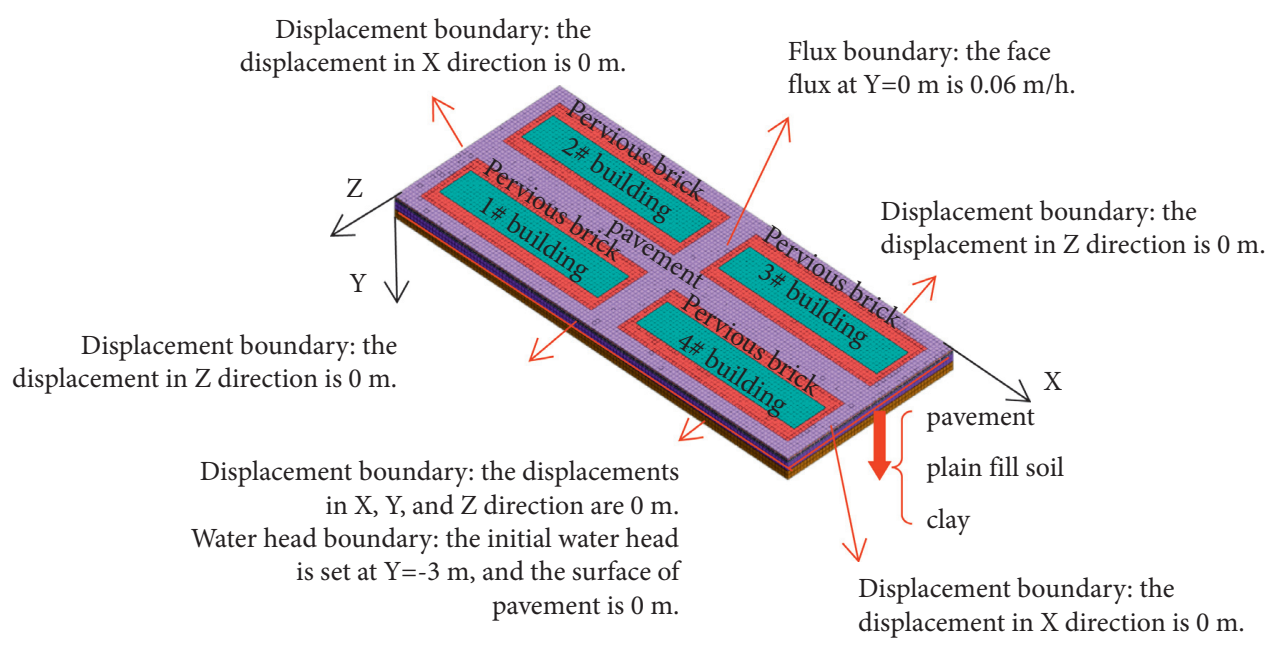

FIGURE 11: Mesh model of building without seepage well.

TABle 5: Parameters of soil layers.

\begin{tabular}{lcccc}
\hline Type & Elastic modulus $(\mathrm{kPa})$ & Initial void ratio & Saturated unit weight $\left(\mathrm{kN} / \mathrm{m}^{3}\right)$ & Permeability coefficient $(\mathrm{m} / \mathrm{s})$ \\
\hline Plain fill & 2258.3 & 0.81 & 21 & $8.0 \times 10^{-5}$ \\
Clay & 3498.0 & 0.51 & 21 & $1.2 \times 10-^{6}$ \\
Building & 3000.0 & 0.50 & 24 & $1.0 \times 1-^{6}$ \\
Pervious brick & 4000.0 & 0.60 & 28 & $2.0 \times 10^{-2}$ \\
Seepage well & 4000.0 & 0.50 & 25 & $2.23 \times 10^{-2}$ \\
\hline
\end{tabular}

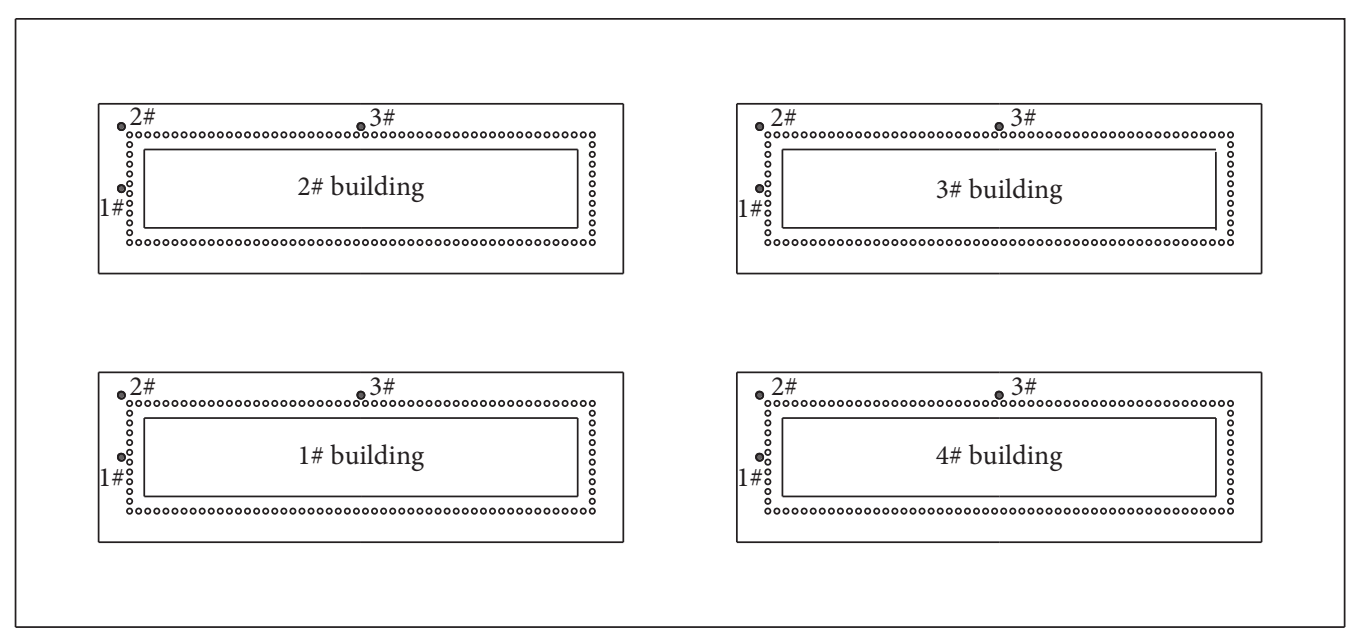

- seepage well

- observation point

FIGURE 12: Buildings layout with seepage wells and observation points in the numerical model.

increases, the difference in the pore water pressures at observation points 1-3 gradually decreases, but the pore water pressure at observation point 2 is larger than that of observation points 1 and 3 . Because observation point 2 is at the corner, both rain contact areas and catchment areas around observation point 2 are larger than that of observation points 1 and 3 .

(2) Total Head. The total head nephograms following $10 \mathrm{~min}$ and 120 min of rainfall are shown in Figure 17. The figures reflect the change in the whole total head of the buildings without any seepage wells.

The change in the total head over $120 \mathrm{~min}$ of rainfall at observation points 1-3 is shown in Figure 18.

Figures 17 and 18 show that the total head of the four buildings is symmetrical without any seepage wells, and the total head at corresponding positions is the same. When the rainfall time is $10 \mathrm{~min}$, the total heads at observation points $1-3$ are $-0.492 \mathrm{~m},-0.864 \mathrm{~m}$, and $-0.655 \mathrm{~m}$, respectively. As the rainfall time increases from $20 \mathrm{~min}$ to $120 \mathrm{~min}$, the 


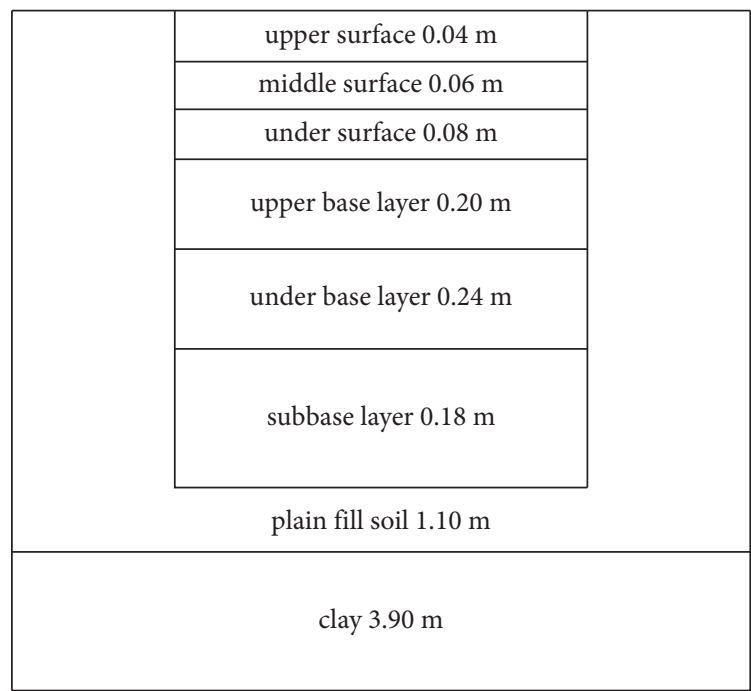

FIGURE 13: Schematic of pavement structure layers in the numerical model.

TABLE 6: Parameters of pavement structure layers.

\begin{tabular}{|c|c|c|c|c|c|c|}
\hline Parameters & Upper surface & Middle surface & Under surface & Upper base layer & Under base layer & Subbase layer \\
\hline Thickness (m) & 0.04 & 0.06 & 0.08 & 0.20 & 0.24 & 0.18 \\
\hline Elastic modulus (MPa) & 1148 & 984 & 820 & 500 & 1500 & 750 \\
\hline Permeability coefficient $(\mathrm{m} / \mathrm{s})$ & $2.13 \times 10^{-6}$ & $1.07 \times 10^{-6}$ & $1.07 \times 10^{-6}$ & $3.0 \times 10^{-5}$ & $3.0 \times 10^{-5}$ & $3.0 \times 10^{-5}$ \\
\hline
\end{tabular}

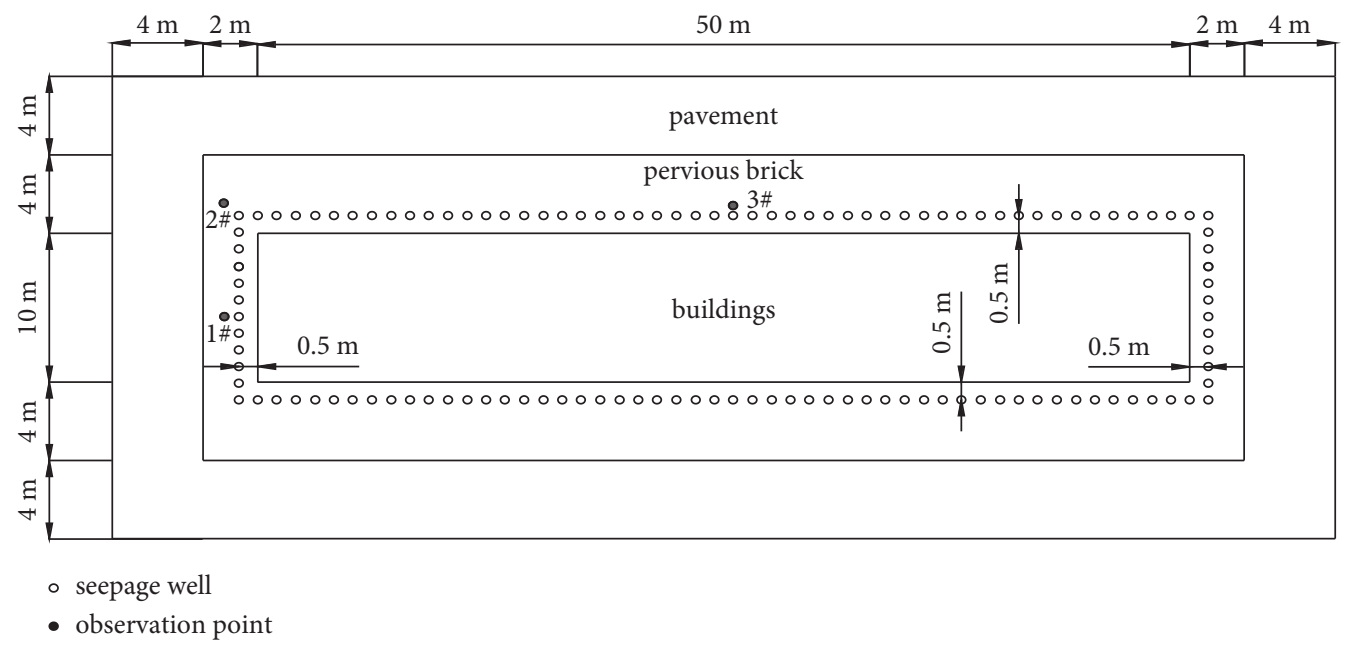

FIGURE 14: Diagram of a single building and surrounding road with seepage wells in the numerical model.

difference in the total heads at observation points 1-3 gradually decreases, and the total heads of observation points 1 and 3 tend to be the same and are less than that of the observation point 2 , which phenomenon is similar to the pore water pressures at observation points 1-3 (Figure 16).

(3) Infiltration Velocity. The infiltration velocity nephograms following $10 \mathrm{~min}$ and $120 \mathrm{~min}$ of rainfall are shown in Figure 19. These illustrations reflect the change in the whole infiltration velocity of the buildings without any seepage wells.

The change in the infiltration velocity over $120 \mathrm{~min}$ of rainfall is analyzed at observation points 1-3 in Figure 20.
Figures 19 and 20 show that the infiltration velocity of the four buildings is symmetrical without any seepage wells, and the infiltration velocity at corresponding positions is the same. When the rainfall time is $10 \mathrm{~min}$, the infiltration velocities of observation points 1 and 3 are $-0.0000745 \mathrm{~m} / \mathrm{s}$ and $-0.0000713 \mathrm{~m} / \mathrm{s}$, which are in accordance with $-0.0000820 \mathrm{~m} / \mathrm{s}$ in the study of Liang et al. [12]. In the study of Liang et al. [12], the test chamber is $0.25 \mathrm{~m}$ in diameter and $0.40 \mathrm{~m}$ in height and includes $0.06 \mathrm{~m}$ of pervious brick, $0.03 \mathrm{~m}$ of sand, $0.10 \mathrm{~m}$ of crushed stone-sand-clay, $0.001 \mathrm{~m}$ of geotextile, and $0.22 \mathrm{~m}$ of clay. The rainfall intensity is $0.059 \mathrm{~m} / \mathrm{h}$. The infiltration velocity of $-0.0000820 \mathrm{~m} / \mathrm{s}$ is obtained at $0.054 \mathrm{~m}$ away from the middle of the test chamber. But the infiltration velocity of observation 

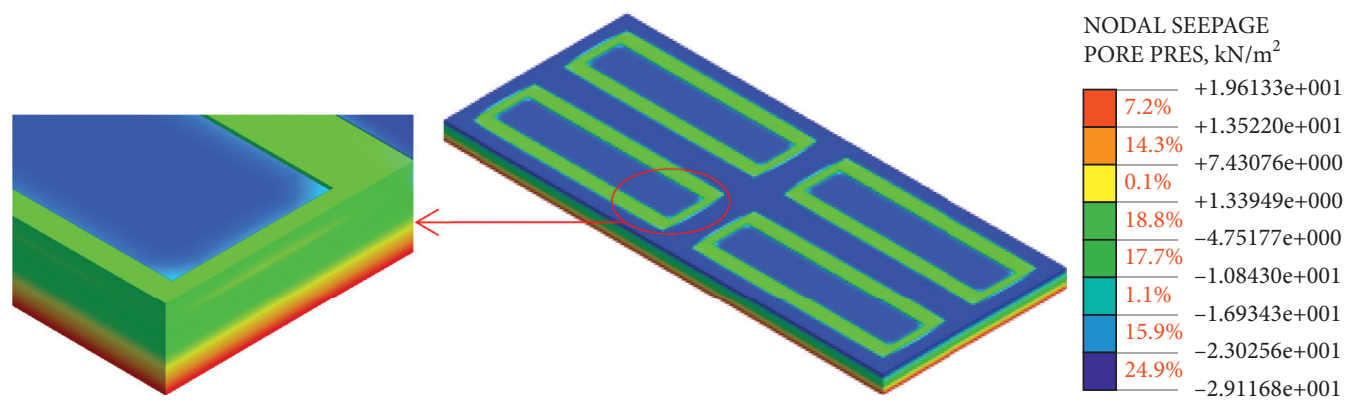

(a)

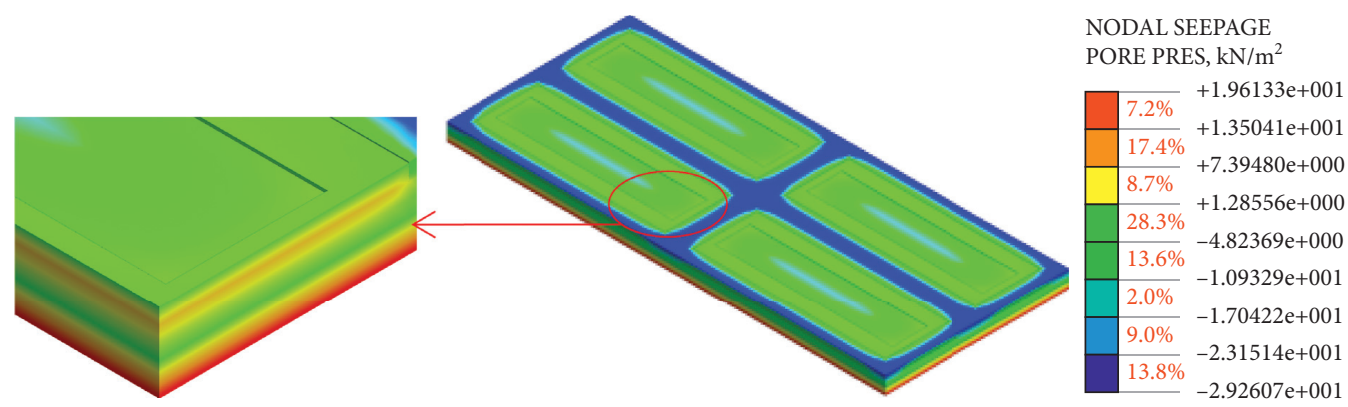

(b)

Figure 15: Pore water pressure nephograms of buildings without seepage wells following (a) 10 min and (b) 120 min of rainfall in the numerical model (the color of the legend represents the pore water pressure range. The value of the legend represents the pore water pressure value. The red \% represents the volume percentage of color legend in the whole numerical model.).

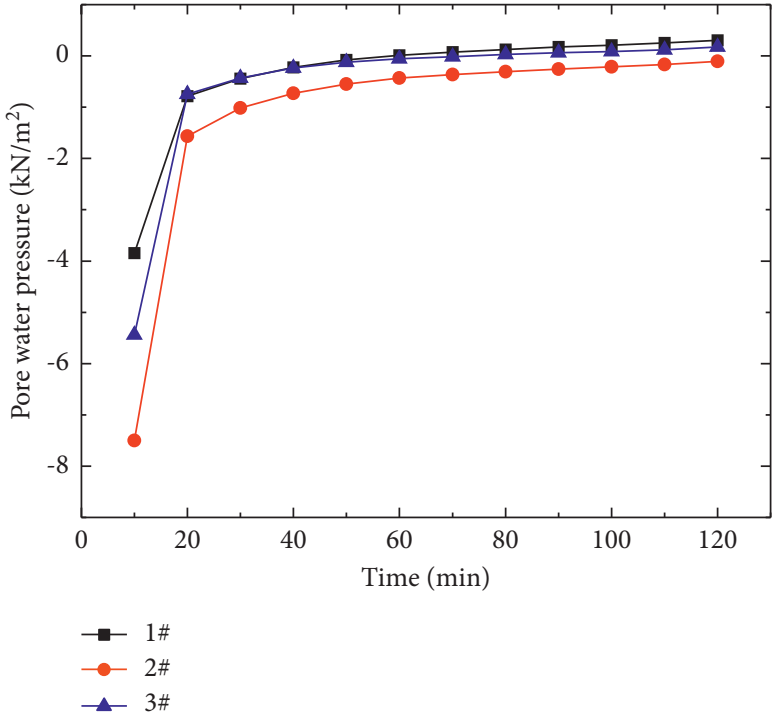

FIgURE 16: Pore water pressure at observation points 1-3 of building 1 without seepage wells around buildings in the numerical model.

point 2 is less than that of observation points 1 and 3 . Because observation point 2 is at the corner, both rain contact areas and catchment areas around observation point 2 are larger than those of observation points 1 and 3 . With an increase in the rainfall time, the difference in the infiltration velocity at observation points 1-3 gradually decreases. When the rainfall time is $120 \mathrm{~min}$, the infiltration velocities at observation points 1 and 3 tend to be stable and are similar.

\subsubsection{Installation of Seepage Wells around Building 1}

(1) Pore Water Pressure. The pore water pressure nephograms following $10 \mathrm{~min}$ and $120 \mathrm{~min}$ of rainfall are shown in Figure 21. These figures reflect the changes in the whole pore water pressure of the buildings when seepage wells are placed around building 1 .

The change in the pore water pressure over $120 \mathrm{~min}$ of rainfall is analyzed at observation points 1-3 in Figure 22.

As shown in Figure 21(a), when the rainfall time is $10 \mathrm{~min}$, the pore water pressures of building 1 are less than those of buildings 2-4 at all observation points. As shown in Figure 21(b), when the rainfall time is $120 \mathrm{~min}$, the pore water pressures of building 1 are greater than those of buildings $2-4$. This is because most rainwater around the seepage wells infiltrates the ground rather than spreading around the surface. As shown in Figure 22, as the rainfall time increases from $10 \mathrm{~min}$ to $30 \mathrm{~min}$, the pore water pressures at observation points between building 1 and buildings 2-4 all significantly decrease. As the rainfall time increases from $30 \mathrm{~min}$ to $120 \mathrm{~min}$, the pore water pressures at observation points between building 1 and buildings 2-4 all gradually decrease and tend to be stable. In addition, Figure 22(a) shows that when the rainfall time is $10 \mathrm{~min}$, the pore water pressures of building 1 at observation points 1 and 3 are $-3.217 \mathrm{kN} / \mathrm{m}^{2}$ and $-3.232 \mathrm{kN} /$ $\mathrm{m}^{2}$, respectively, which are consistent with $-2.836 \mathrm{kN} / \mathrm{m}^{2}$ in the research of Hou et al. [21]. In the research of Hou et al. [21], the site of the in-situ infiltration test is located in the Hai River Education Park, Jinnan District Nankai University, Tianjin. The site is $3 \mathrm{~m} \times 3 \mathrm{~m}$ area and includes 

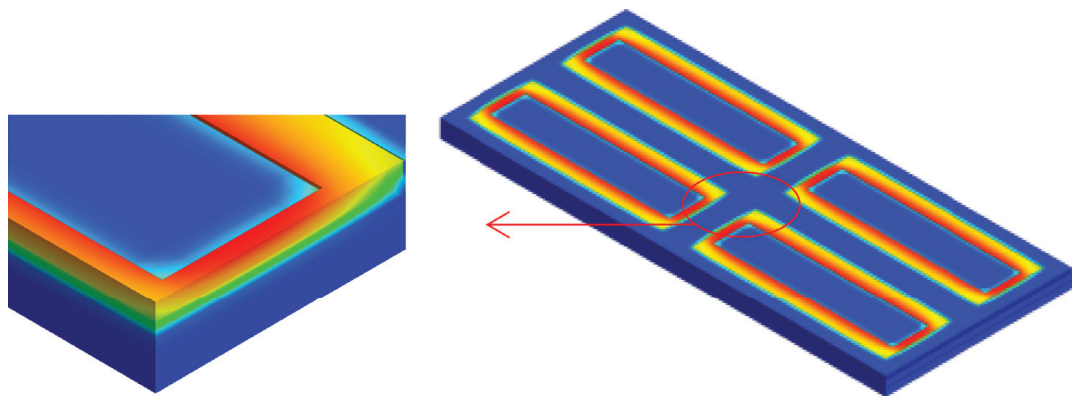

NODAL SEEPAGE TOTAL HEAD, $\mathrm{m}$

(a)
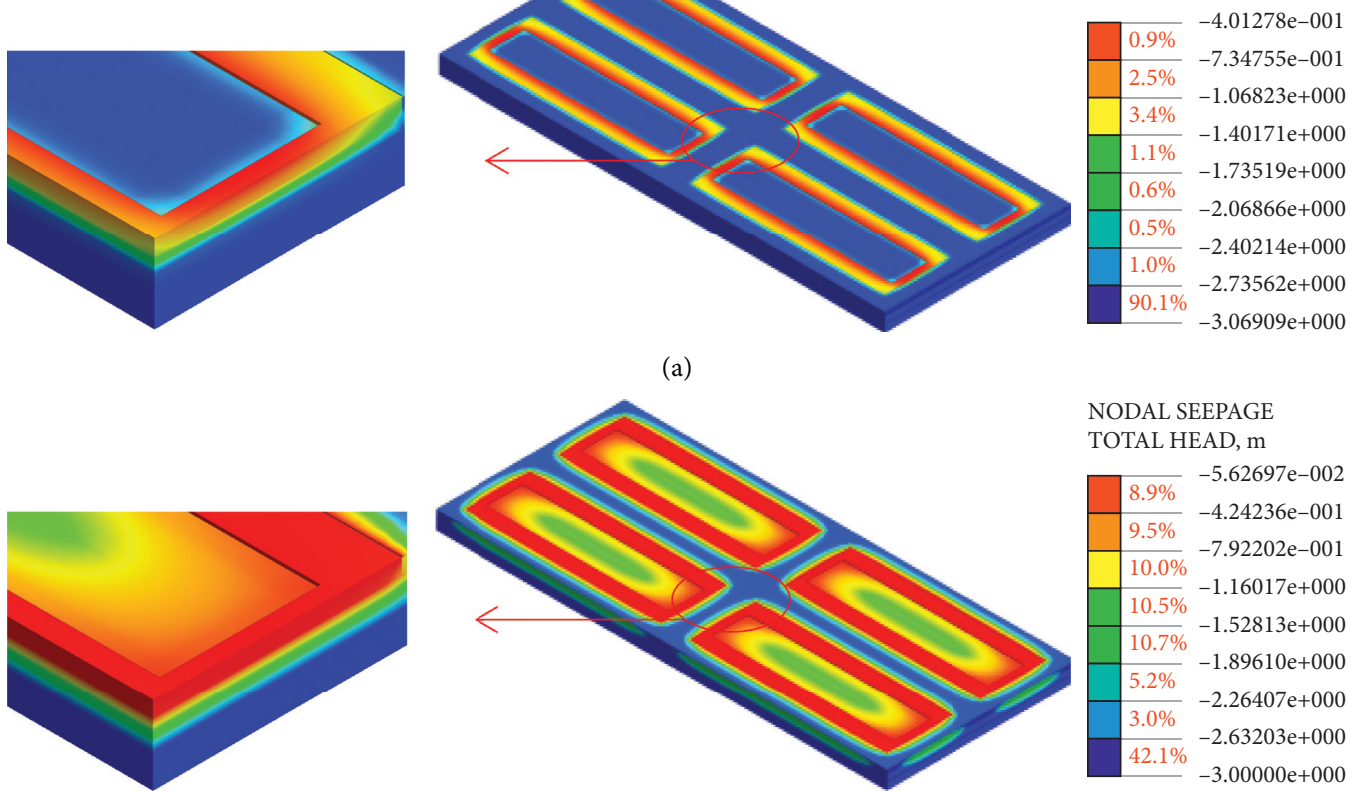

NODAL SEEPAGE TOTAL HEAD, $\mathrm{m}$

(b)

Figure 17: Total head nephograms of buildings without seepage wells after (a) 10 min and (b) 120 min of rainfall in the numerical model (the color of the legend represents the total head range. The value of the legend represents the total head value. The red \% represents the volume percentage of color legend in the whole numerical model.).

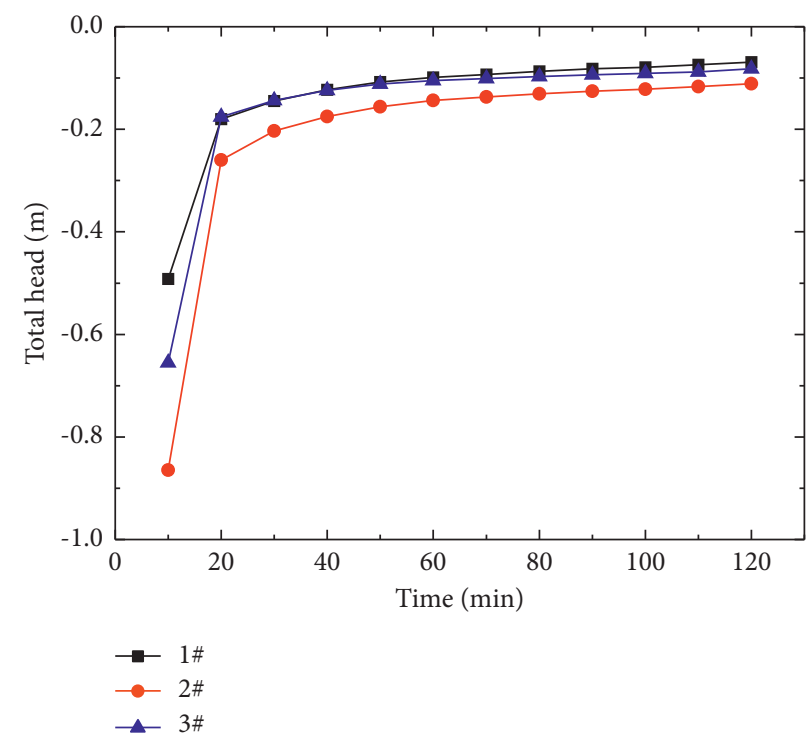

Figure 18: Total head at observation points $1-3$ of building 1 without seepage wells around buildings in the numerical model.

$1.1 \mathrm{~m}$ of plain fill soil and $3.9 \mathrm{~m}$ of clay. The rainfall intensity is $0.058 \mathrm{~m} / \mathrm{h}$. The seepage well is $0.1 \mathrm{~m}$ in diameter and $1 \mathrm{~m}$ in height and is spaced at $1 \mathrm{~m}$ intervals with the previous brick on the top of the seepage well. The pore water pressure of $-2.836 \mathrm{kN} / \mathrm{m}^{2}$ is obtained at the middle of two adjacent seepage wells. Figure 12 shows that observation points 1 and 2 for building 4 are adjacent to the seepage wells of building 1 , but the pore water pressures of building 4 at observation points 1 and 2 (Figure 22(b)) were similar to that of Figure 16. Because there is a long distance apart between building 4 and building 1 , and the pore water pressures of building 4 are not affected by the seepage well of building 1 .

(2) Total Head. The total head nephograms following $10 \mathrm{~min}$ and $120 \mathrm{~min}$ of rainfall are shown in Figure 23. These reflect the changes in the total head of the buildings with seepage wells placed around building 1 . 


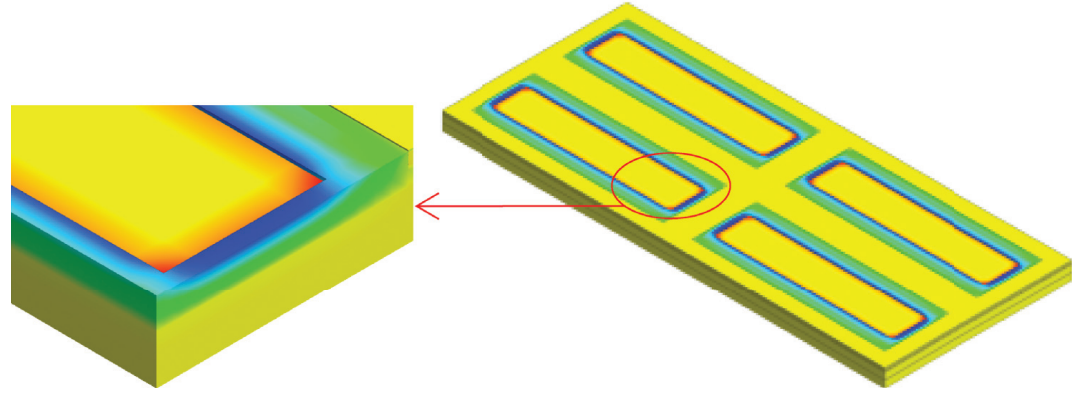

(a)

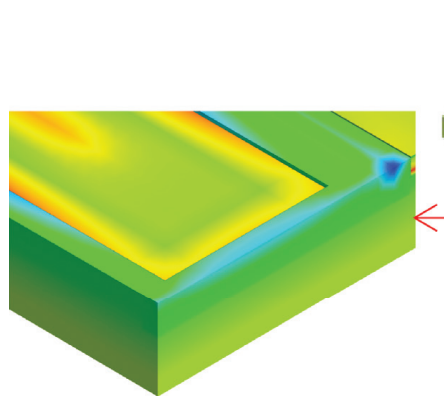

SEEPAGE FLOW FLOW VEL-Z, m/sec

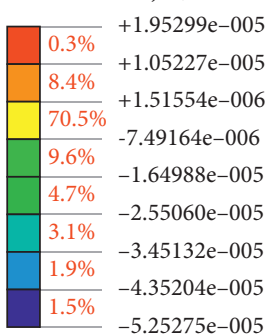

SEEPAGE FLOW FLOW VEL-Z, m/sec

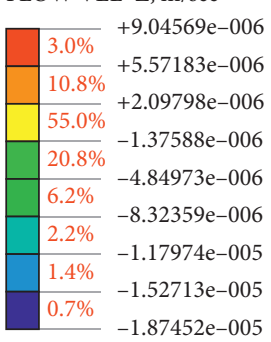

(b)

FIGURE 19: Infiltration velocity nephograms of buildings without seepage wells after (a) $10 \mathrm{~min}$ and (b) 120 min of rainfall in the numerical model (the color of the legend represents the infiltration velocity range. The value of the legend represents the infiltration velocity value. The red \% represents the volume percentage of color legend in the whole numerical model.).

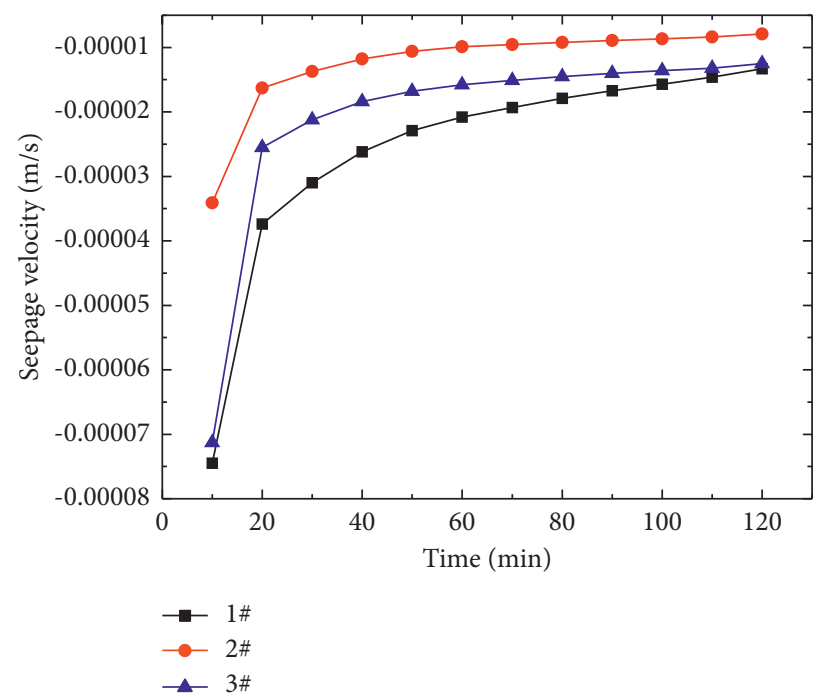

FIGURE 20: Infiltration velocity at observation points 1-3 of building 1 without seepage wells around buildings in the numerical model.

The change in the total head over 120 min of rainfall is analyzed at observation points $1-3$ in Figure 24.

As shown in Figures 23 and 24, when the rainfall time is $10 \mathrm{~min}$, the total heads of building 1 are less than those of buildings 2-4 at all observation points. As the rainfall time increases, the difference in the total head between building 1 and buildings $2-4$ gradually decreases. When the rainfall time is $120 \mathrm{~min}$, the total heads of building 1 are greater than those of buildings $2-4$. This is because most rainwater around the seepage wells infiltrates the ground rather than spreading around the surface. In addition, observation points 1 and 2 of building 4 are adjacent to the seepage well of building 1 , but the total heads of building 4 at these observation points are not affected by the seepage well of building 1 because they are a long distance apart.

(3) Infiltration Velocity. The infiltration velocity nephograms following $10 \mathrm{~min}$ and $120 \mathrm{~min}$ of rainfall are shown in Figure 25. These nephograms reflect the change in the whole infiltration velocity of the buildings with seepage wells placed around building 1 . 

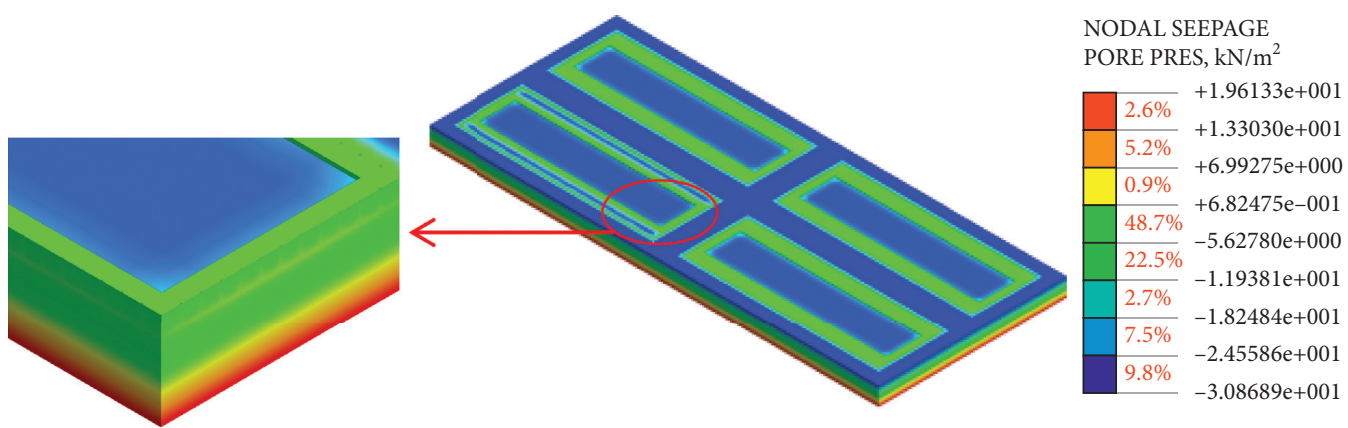

NODAL SEEPAGE PORE PRES, $\mathrm{kN} / \mathrm{m}^{2}$

(a)
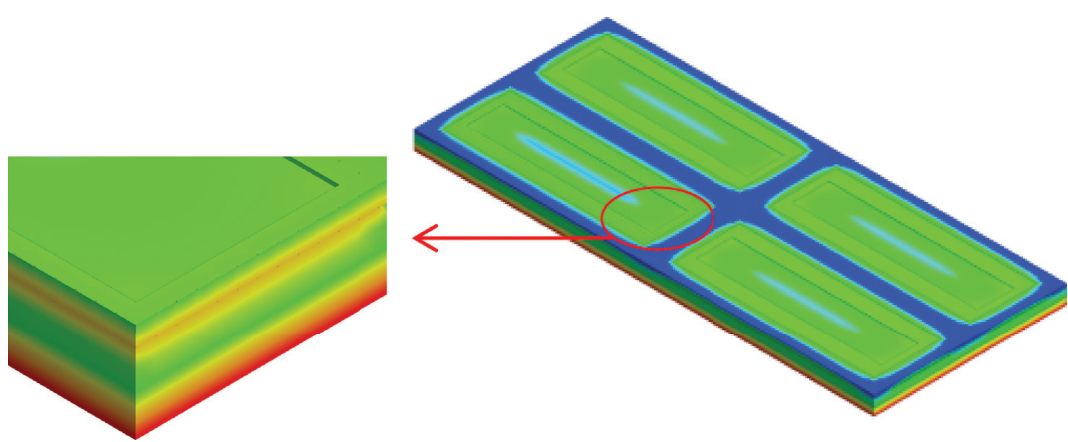

NODAL SEEPAGE PORE PRES, $\mathrm{kN} / \mathrm{m}^{2}$

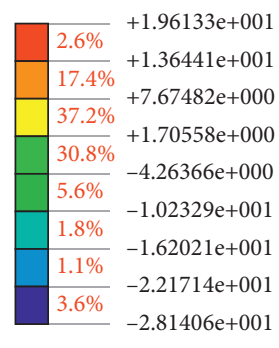

(b)

Figure 21: Pore water pressure nephograms of buildings when seepage wells are placed around building 1 following (a) 10 min and (b) $120 \mathrm{~min}$ of rainfall in the numerical model (the color of the legend represents the pore water pressure range. The value of the legend represents the pore water pressure value. The red \% represents the volume percentage of color legend in the whole numerical model.).

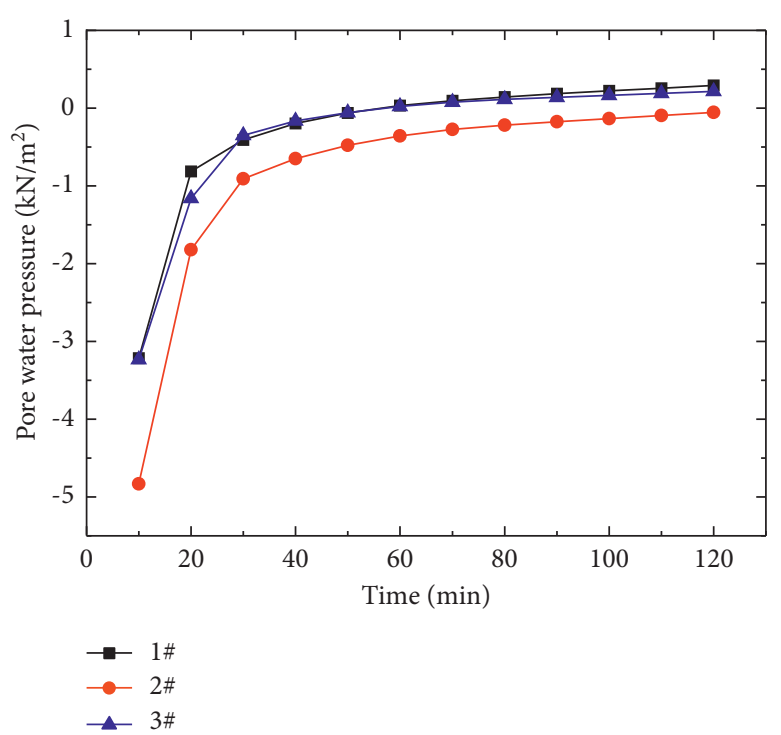

(a)

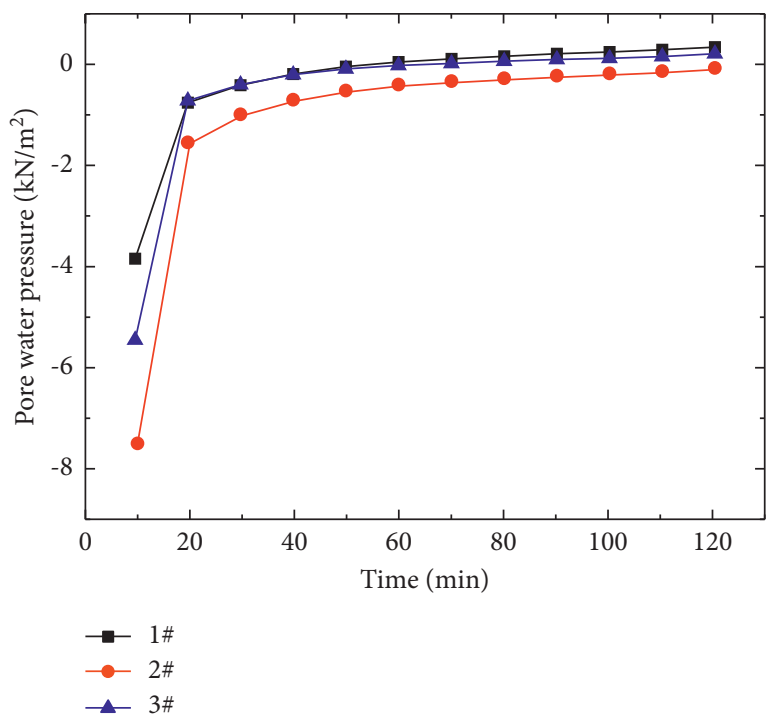

(b)

FIGURE 22: Pore water pressure at observation points 1-3 of (a) building 1 and (b) buildings $2-4$ with seepage wells placed around building 1 in the numerical model.

The change in the infiltration velocity over $120 \mathrm{~min}$ of rainfall is analyzed at observation points 1-3 in Figure 26.

As shown in Figures 25 and 26, when the rainfall time is $10 \mathrm{~min}$, the infiltration velocities of building 1 at observation points 1 and 3 are $-0.00331 \mathrm{~m} / \mathrm{s}$ and $-0.00402 \mathrm{~m} / \mathrm{s}$, which are in line with $-0.00340 \mathrm{~m} / \mathrm{s}$ in the findings of Liang et al. [12]. In the findings of Liang et al. [12], the test chamber is $0.25 \mathrm{~m}$ in diameter and $0.40 \mathrm{~m}$ in height and includes $0.06 \mathrm{~m}$ of pervious brick, $0.03 \mathrm{~m}$ of sand, $0.10 \mathrm{~m}$ of crushed stone-sand-clay, $0.001 \mathrm{~m}$ of geotextile, and $0.22 \mathrm{~m}$ of clay. The rainfall intensity is $0.059 \mathrm{~m} / \mathrm{h}$. The seepage well is $0.076 \mathrm{~m}$ in diameter and 


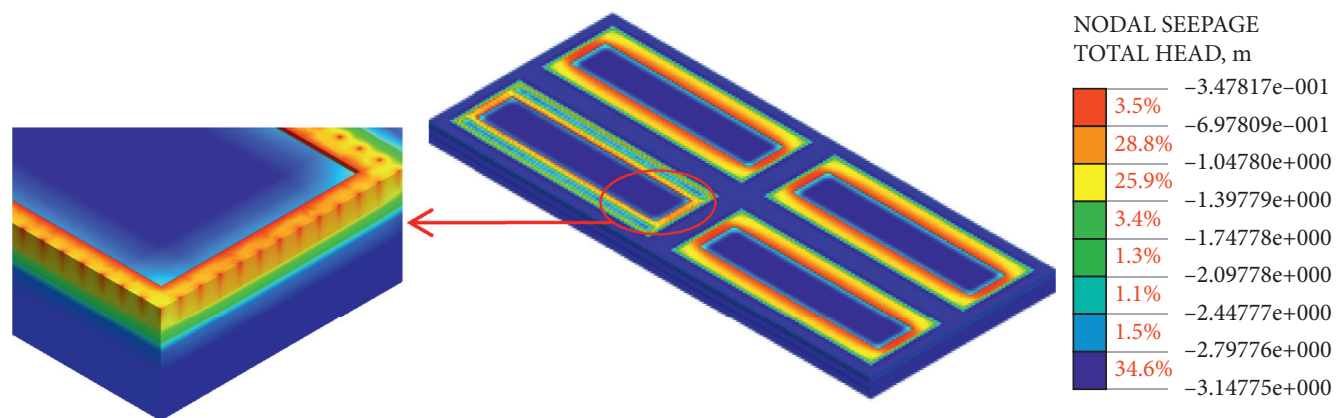

(a)

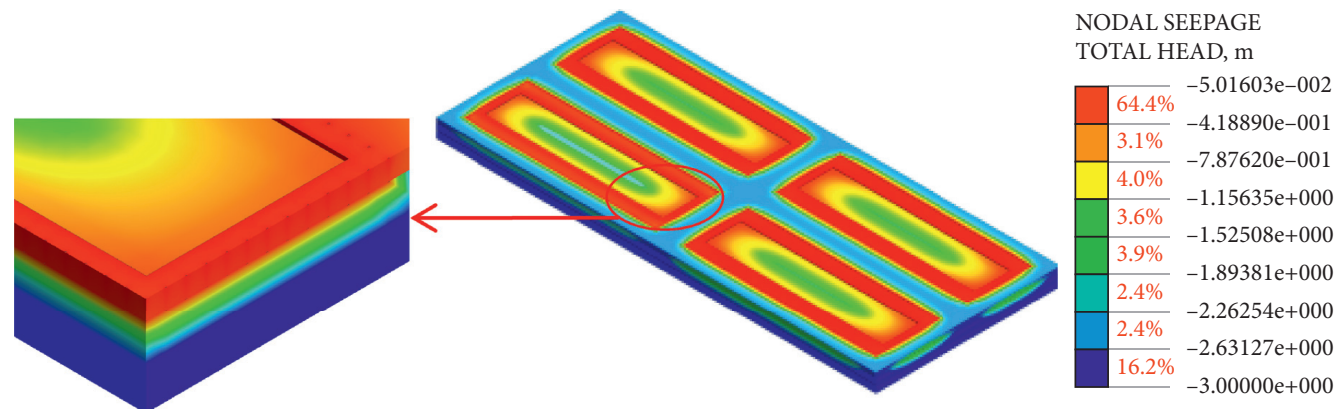

(b)

FIGURE 23: Total head nephograms of buildings with seepage wells placed around building 1 following (a) 10 min and (b) 120 min of rainfall in the numerical model (the color of the legend represents the total head range. The value of the legend represents the total head value. The red \% represents the volume percentage of color legend in the whole numerical model.).

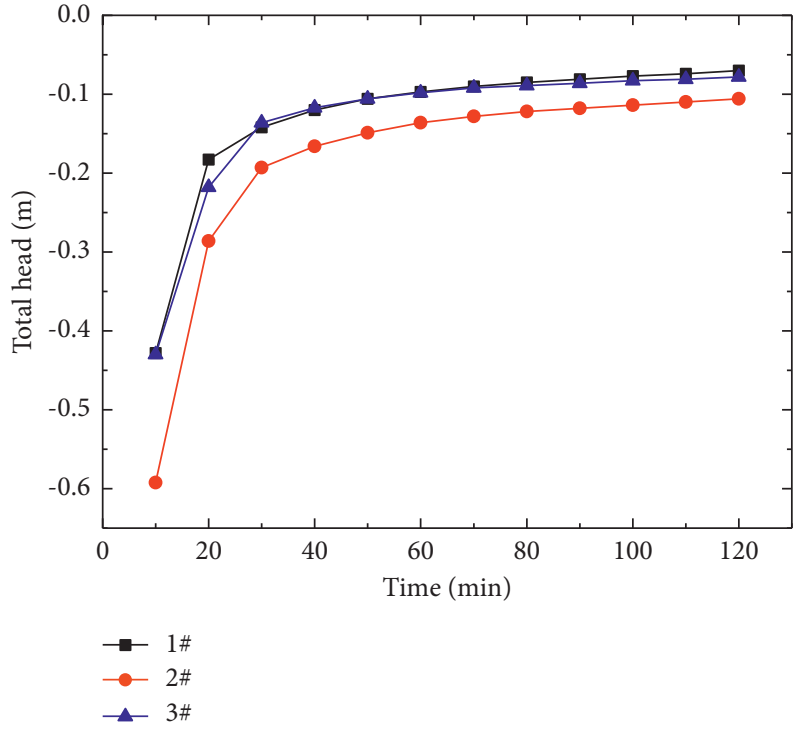

(a)

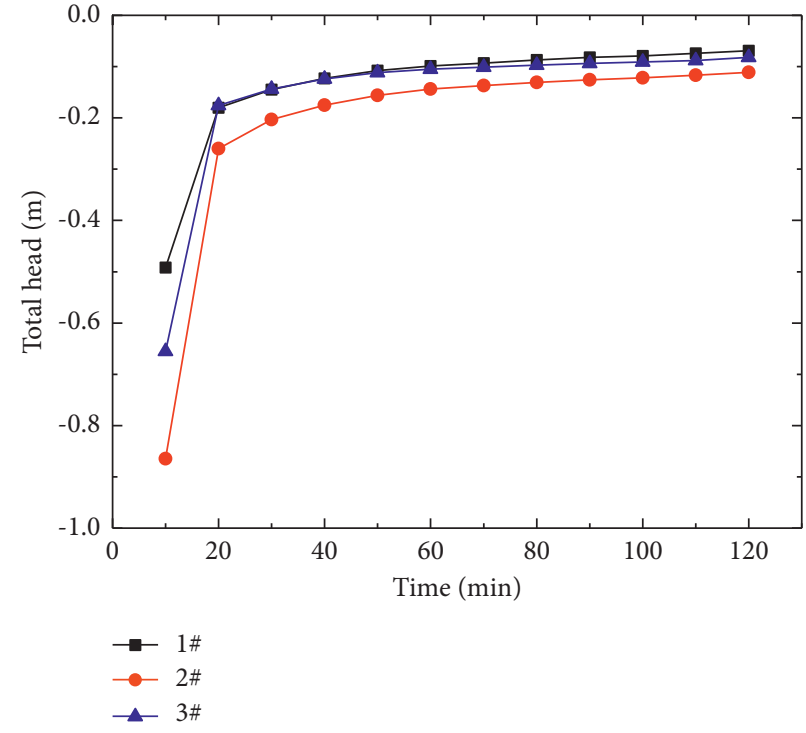

(b)

Figure 24: Total head at observation points $1-3$ of (a) building 1 and (b) buildings $2-4$ with seepage wells placed around building 1 in the numerical model.

$0.3 \mathrm{~m}$ in height and is at the middle of the test chamber. The infiltration velocity of $-0.00340 \mathrm{~m} / \mathrm{s}$ is obtained at $0.054 \mathrm{~m}$ away from the middle of the test chamber. As the rainfall time increases, the difference in infiltration velocity between building 1 and buildings $2-4$ gradually decreases. When the rainfall time is $120 \mathrm{~min}$, the infiltration velocities of building 1 are greater than those of buildings $2-4$. This is because most rainwater around the seepage wells infiltrates the ground rather than spreading around the surface. In addition, observation points 1 and 2 of building 4 are adjacent to the seepage wells of building 1 , but the infiltration velocities of building 4 at these observation points are not affected by the seepage wells of building 1 because they are a long distance apart. 


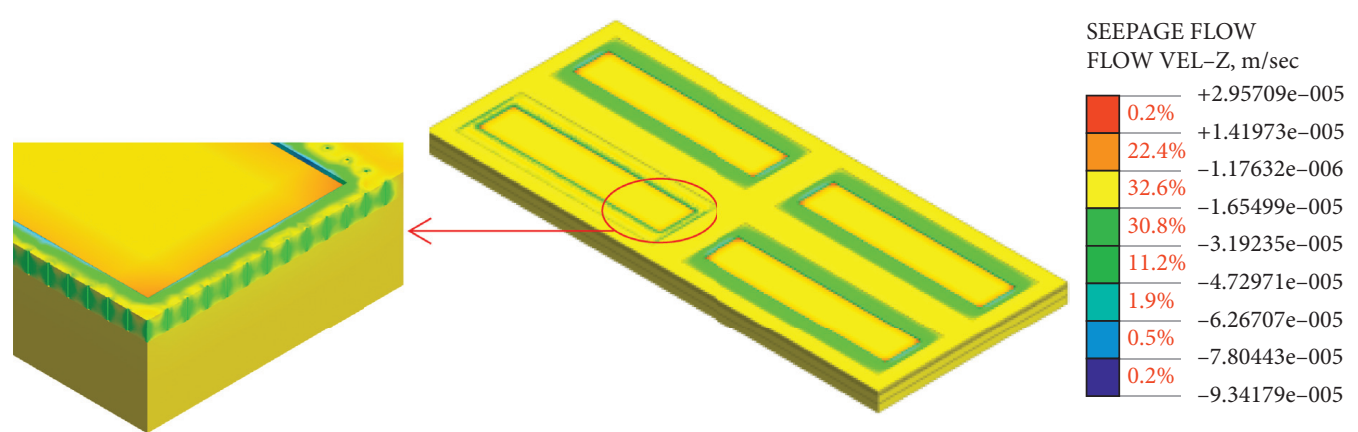

(a)

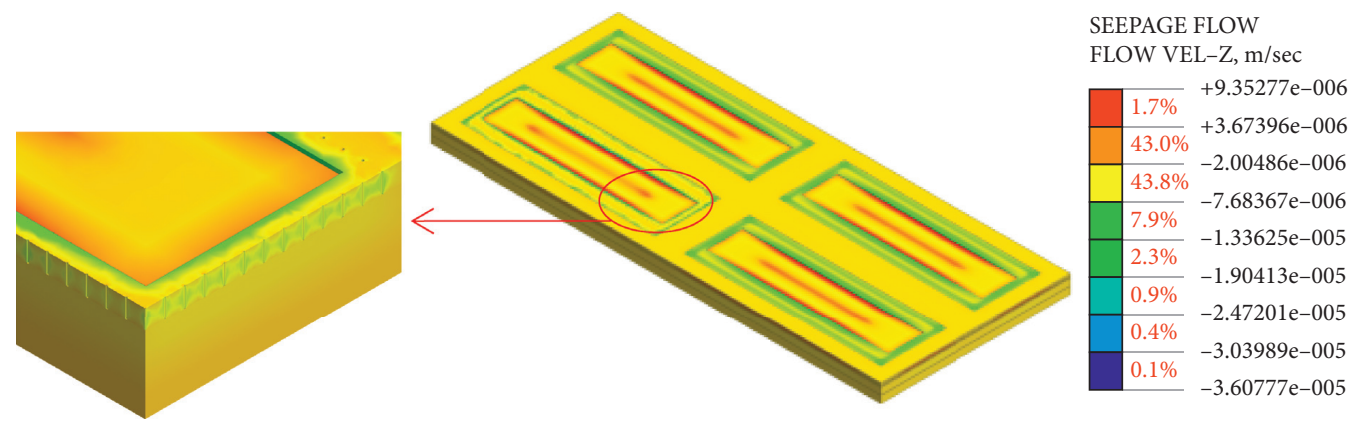

(b)

FIGURE 25: Infiltration velocity nephograms of buildings with seepage wells placed around building 1 after (a) 10 min and (b) 120 min of rainfall in the numerical model (the color of the legend represents the infiltration velocity range. The value of the legend represents the infiltration velocity value. The red \% represents the volume percentage of color legend in the whole numerical model.).

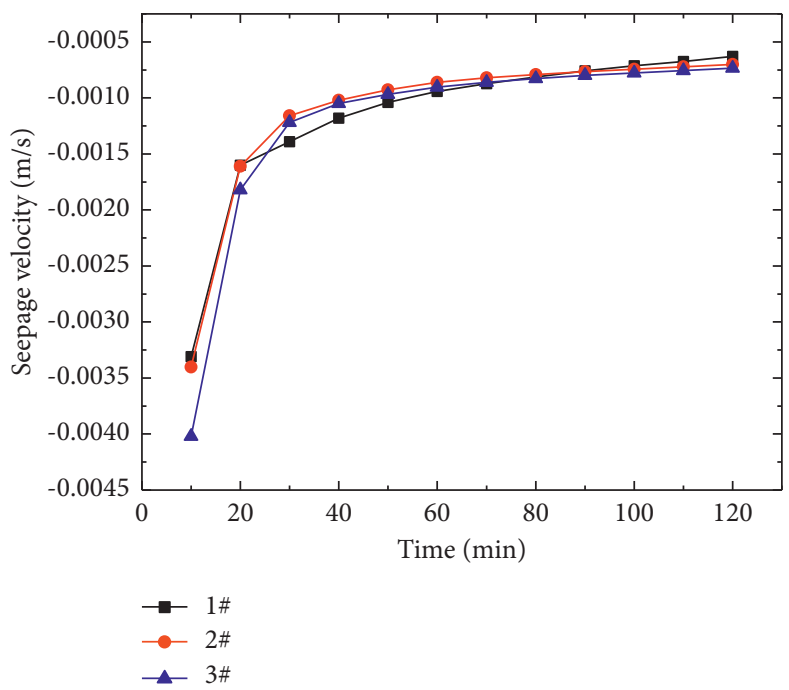

(a)

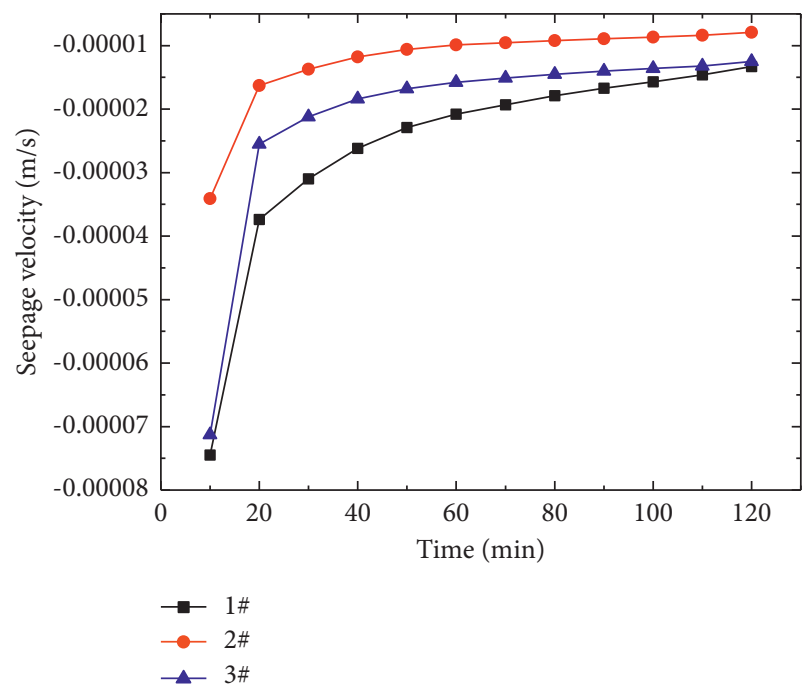

(b)

FIGURE 26: Infiltration velocity at observation points $1-3$ of (a) building 1 and (b) buildings $2-4$ with seepage wells placed around building 1 in the numerical model.

\subsubsection{Installation of Seepage Wells around Buildings 1 and 2}

(1) Pore Water Pressure. The pore water pressure nephograms following $10 \mathrm{~min}$ and $120 \mathrm{~min}$ of rainfall are shown in Figure 27. These reflect the change in the whole pore water pressure of the buildings when seepage wells are placed around buildings 1 and 2 .
The changes in the pore water pressure over $120 \mathrm{~min}$ of rainfall are analyzed at observation points 1-3 in Figure 28.

Figures 27 and 28 show that the pore water pressure nephograms of buildings 1 and 2 are initially different but eventually similar to those of buildings 3 and 4 . After $10 \mathrm{~min}$ of rainfall, the pore water pressures at observation points 1 and 3 for buildings 1 and 2 (Figure 28(a)) are similar to those 

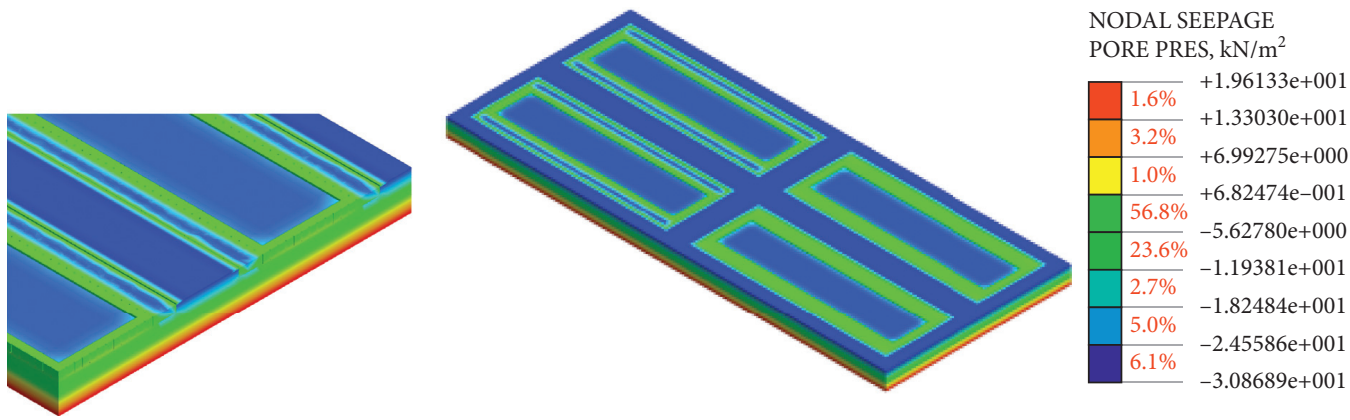

(a)

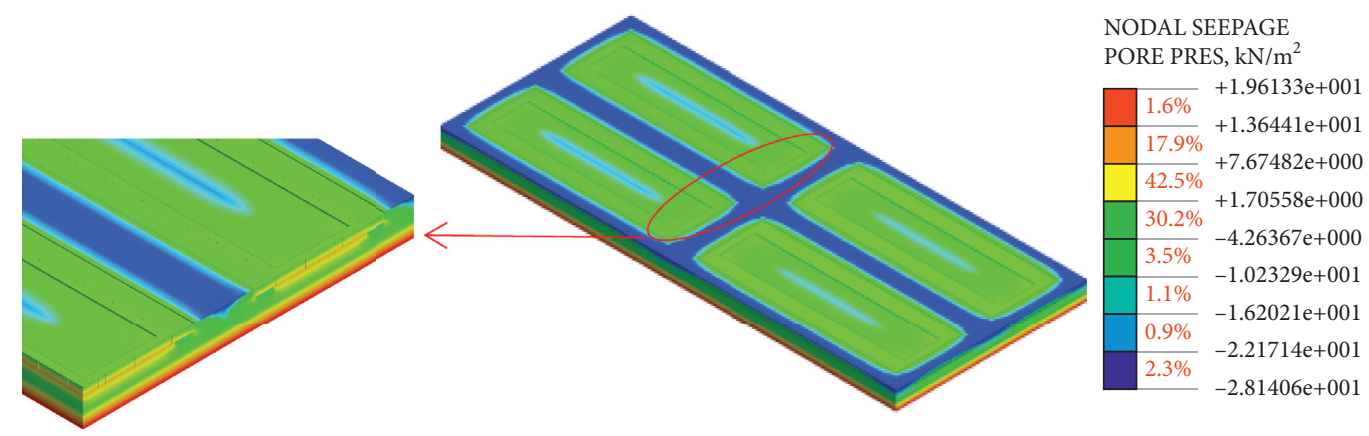

(b)

FIGURE 27: Pore water pressure nephograms of buildings with seepage wells placed around buildings 1 and 2 after (a) 10 min and (b) 120 min of rainfall in the numerical model (the color of the legend represents the pore water pressure range. The value of the legend represents the pore water pressure value. The red \% represents the volume percentage of color legend in the whole numerical model.).

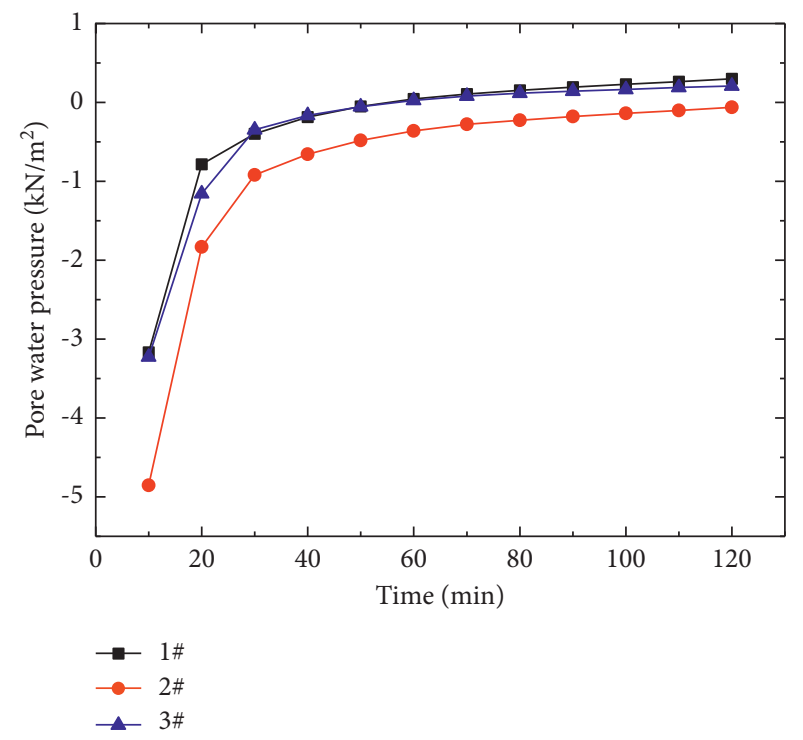

(a)

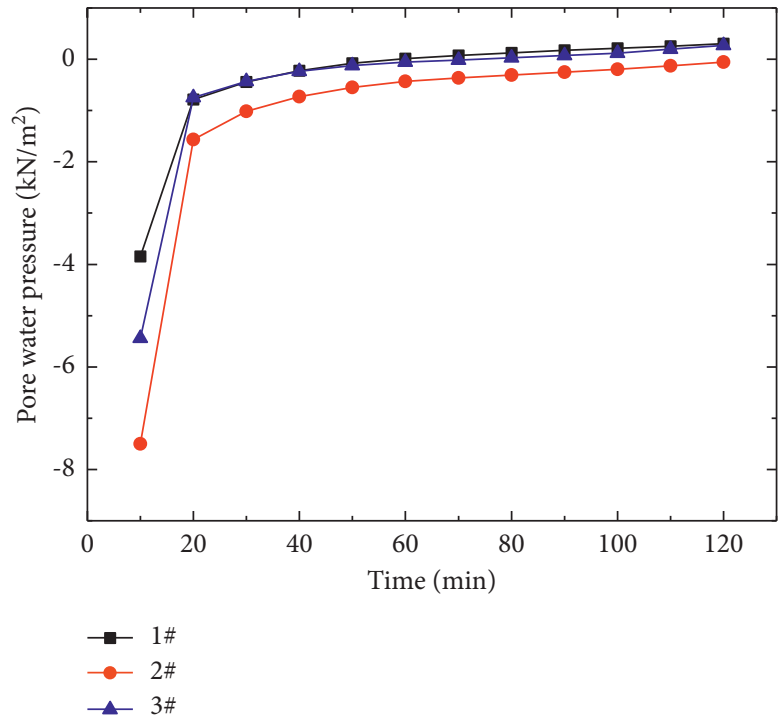

(b)

FIGURE 28: Pore water pressure at observation points 1-3 of (a) buildings 1-2 and (b) buildings 2-4 with seepage wells placed around buildings 1 and 2 in the numerical model.

at observation points 1 and 3 for buildings 1 (Figure 22(a)), which is in compliance with the findings of Hou et al. [21]. With increasing rainfall time, the difference in pore water pressures between buildings 1 and 2 and buildings 3 and 4 gradually decreases. After $120 \mathrm{~min}$ of rainfall, the pore water pressures of buildings 1 and 2 are greater than those of buildings 3 and 4 . This is because most rainwater around the seepage wells infiltrates the ground rather than spreading around the surface. In addition, observation points 1 and 2 at buildings 3 and 4 are adjacent to the seepage wells of buildings 1 and 2, but the pore water pressures are not affected by these seepage wells because they are a long distance apart. 


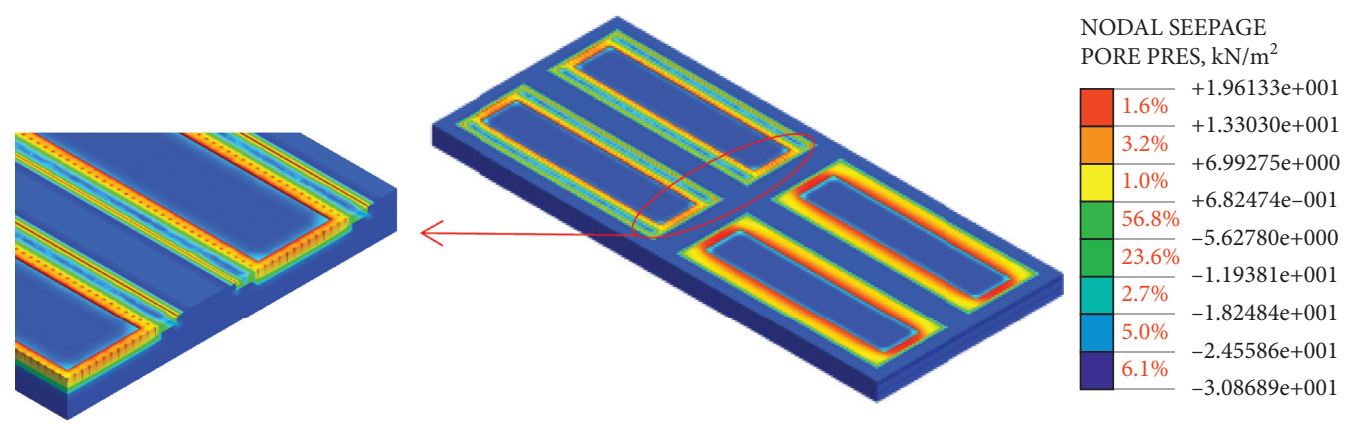

(a)

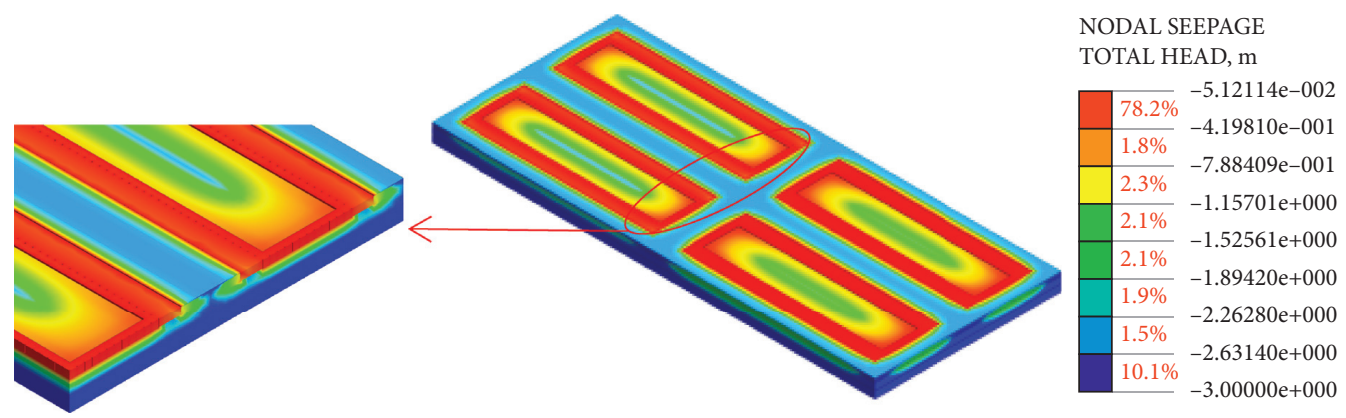

(b)

FIGURE 29: Total head nephograms of buildings with seepage wells placed around buildings 1 and 2 after (a) 10 min and (b) 120 min of rainfall in the numerical model (the color of the legend represents the total head range.

(2) Total Head. The total head nephograms after $10 \mathrm{~min}$ and $120 \mathrm{~min}$ of rainfall are shown in Figure 29. These images reflect the change in the total head of the buildings when seepage wells are placed around buildings 1 and 2 .

The value of the legend represents the total head value. The red \% represents the volume percentage of color legend in the whole numerical model.).

The change in the total head over $120 \mathrm{~min}$ of rainfall is analyzed at observation points 1-3 in Figure 30.

Figures 29 and 30 show that the total head nephograms of buildings 1 and 2 are initially different but eventually similar to those of buildings 3 and 4 . When the rainfall time is $10 \mathrm{~min}$, the total heads at observation points $1-3$ for buildings 1 and 2 vary by $0.068 \mathrm{~m}, 0.271 \mathrm{~m}$, and $0.226 \mathrm{~m}$. As the rainfall time increases, the difference in the total head between buildings 1 and 2 and buildings 3 and 4 gradually decreases. When the rainfall time is $120 \mathrm{~min}$, the total heads of buildings 1 and 2 are greater than those of buildings 3 and 4 . This is because most rainwater around the seepage wells infiltrates the ground rather than spreading around the surface. As shown in Figure 12, observation points 1 and 2 of buildings 3 and 4 are adjacent to the seepage wells of buildings 1 and 2 . However, the total heads at observation points 1 and 2 of buildings 3 and 4 are similar to those of Figure 16 because the distances between buildings are large. In a word, the influence range of seepage wells is limited. When the distance between buildings exceeds the influence range of seepage wells, seepage wells have little effect on the total head of adjacent buildings, which also verifies the results of pore water pressures.
(3) Infiltration Velocity. The infiltration velocity nephograms following $10 \mathrm{~min}$ and $120 \mathrm{~min}$ of rainfall are shown in Figure 31. These figures reflect the change in the infiltration velocity of the buildings when seepage wells are placed around buildings 1 and 2 .

The change in the infiltration velocity over $120 \mathrm{~min}$ of rainfall is analyzed at observation points $1-3$ in Figure 32.

Figures 31 and 32 show that the infiltration velocities of buildings 1 and 2 are initially different but eventually similar to those of buildings 3 and 4 . After $10 \mathrm{~min}$ of rainfall, the infiltration velocities at observation points 1 and 3 for buildings 1 and 2 (Figure 32(a)) are similar to those at observation points 1 and 3 for buildings 1 (Figure 26(a)), which agrees with the research of Liang et al. [12]. As the rainfall time increases, the difference in the infiltration velocity between buildings 1 and 2 and buildings 3 and 4 gradually decreases. When the rainfall time is $120 \mathrm{~min}$, the infiltration velocities of buildings 1 and 2 are greater than those of buildings 3 and 4 . This is because most rainwater around the seepage wells infiltrates the ground rather than spreading around the surface. In addition, observation points 1 and 2 of buildings 3 and 4 are adjacent to the seepage wells of buildings 1 and 2 , but the infiltration velocities at these observation points are not affected by the seepage wells because they are a long distance apart.

4.3.4. Analysis of Influence Range of Seepage Wells in Buildings. To further analyze the influence range of the seepage well, nine observation points are considered, as shown in Figure 33. 


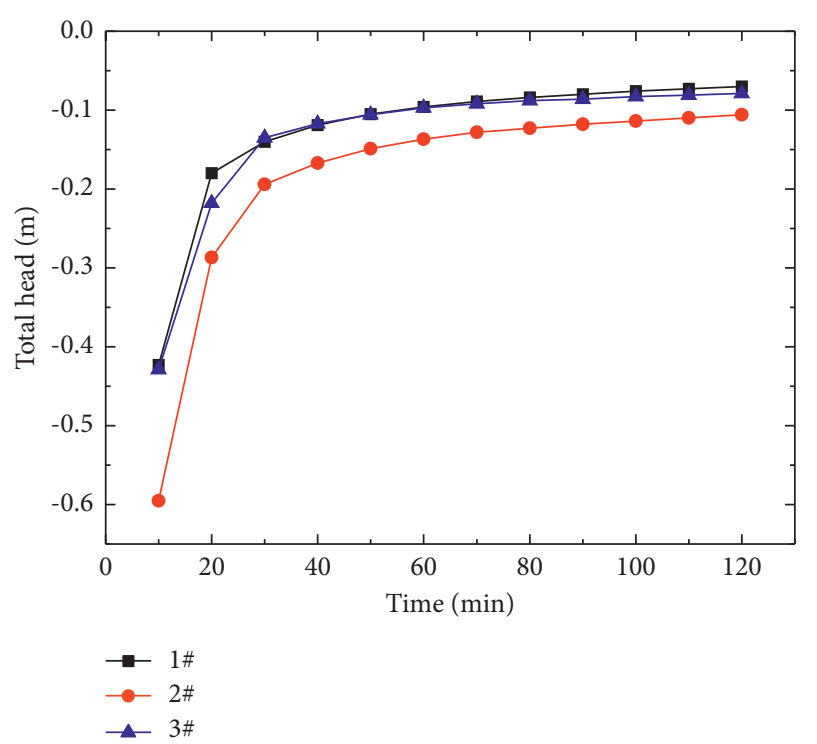

(a)

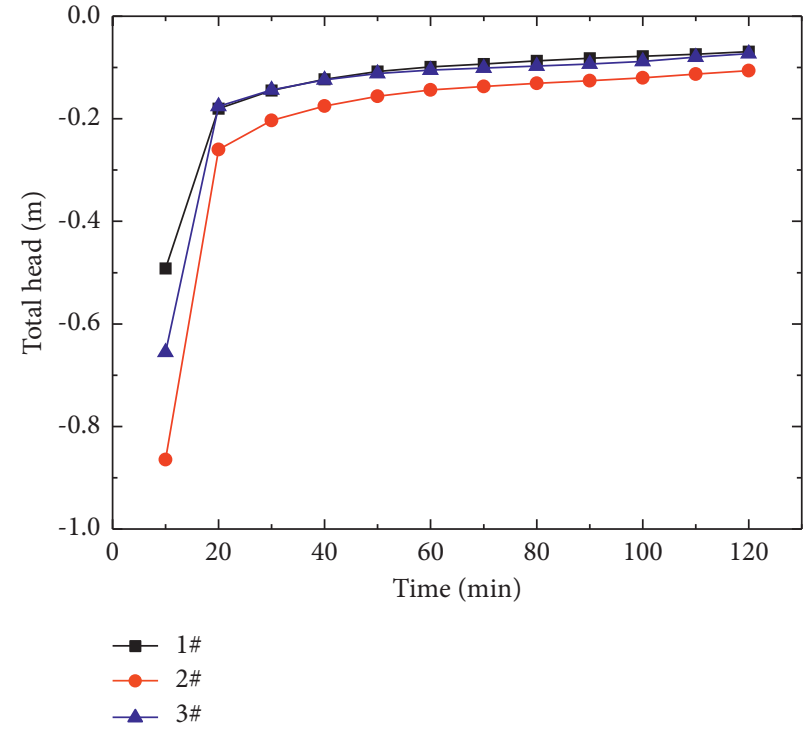

(b)

FIgURE 30: Total head at observation points 1-3 of (a) buildings 1-2 and (b) buildings 2-4 with seepage wells placed around buildings 1 and 2 in the numerical model.

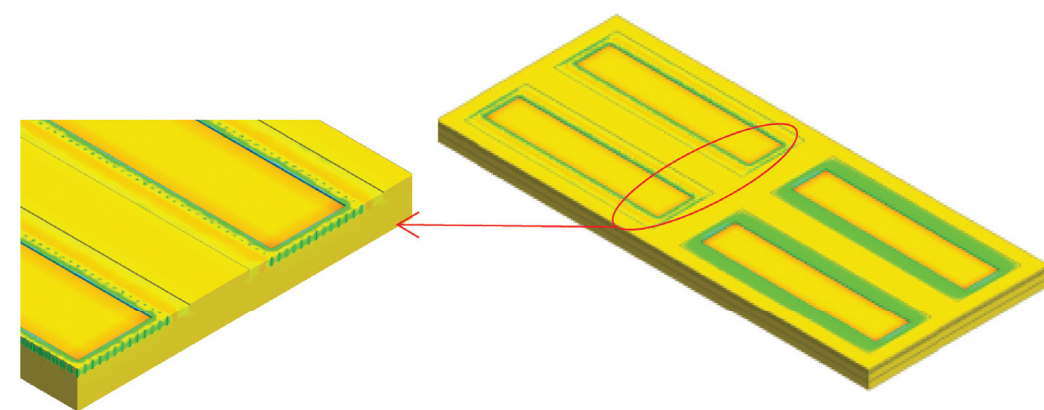

(a)

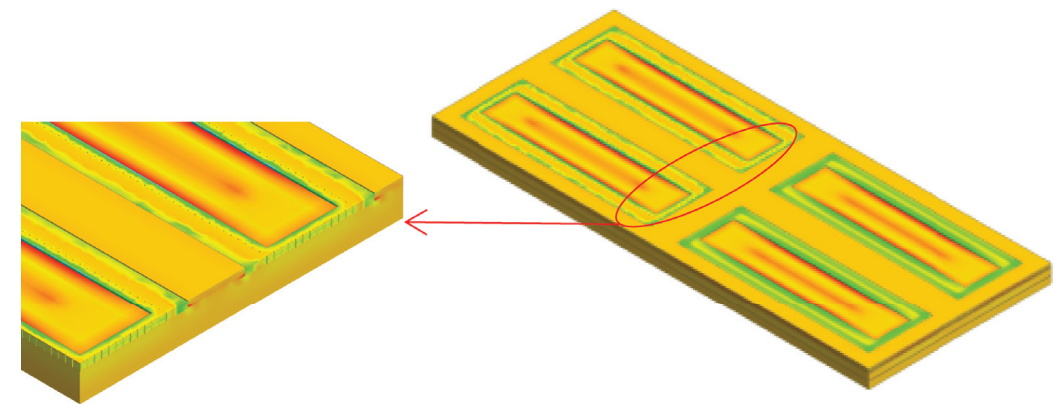

(b)
SEEPAGE FLOW FLOW VEL-Z, $\mathrm{m} / \mathrm{sec}$

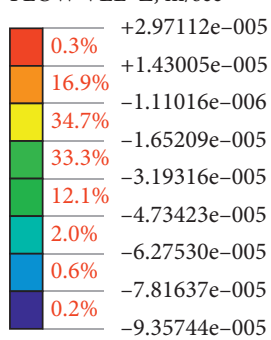

SEEPAGE FLOW FLOW VEL-Z, m/sec

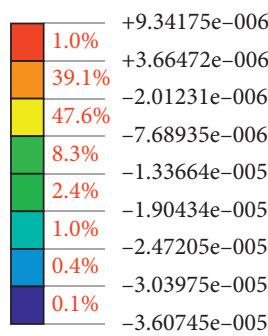

FIGURE 31: Infiltration velocity nephograms of buildings with seepage wells placed around buildings 1 and 2 after (a) 10 min and (b) 120 min of rainfall in the numerical model (the color of the legend represents the infiltration velocity range. The value of the legend represents the infiltration velocity value. The red \% represents the volume percentage of color legend in the whole numerical model.).

(1) Without Seepage Wells. The changes in the pore water pressure over $120 \mathrm{~min}$ of rainfall at observation points 6-14 in the absence of seepage wells are shown in Figure 34.

As shown in Figure 34, due to the symmetrical nature of the model, the pore water pressures at observation points 6 , 7,13 , and 14 are similar, as are those at observation points 8 and 12 and at observation points 10 and 11 . As the rainfall time increases from $10 \mathrm{~min}$ to $50 \mathrm{~min}$, the pore water pressures are similar at each observation point. Observation points 10 and 11 record the highest pore water pressures, closely followed by observation points 8 and 12 . Observation points $6,7,13$, and 14 have lower pore water pressures. The lowest pore water pressure occurs at observation point 9 , and remains almost unchanged. 


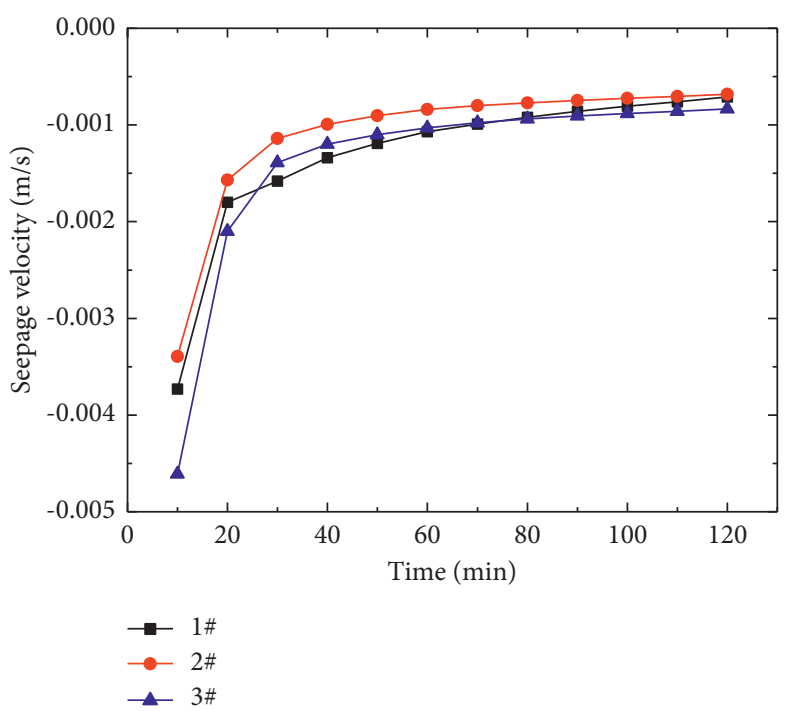

(a)

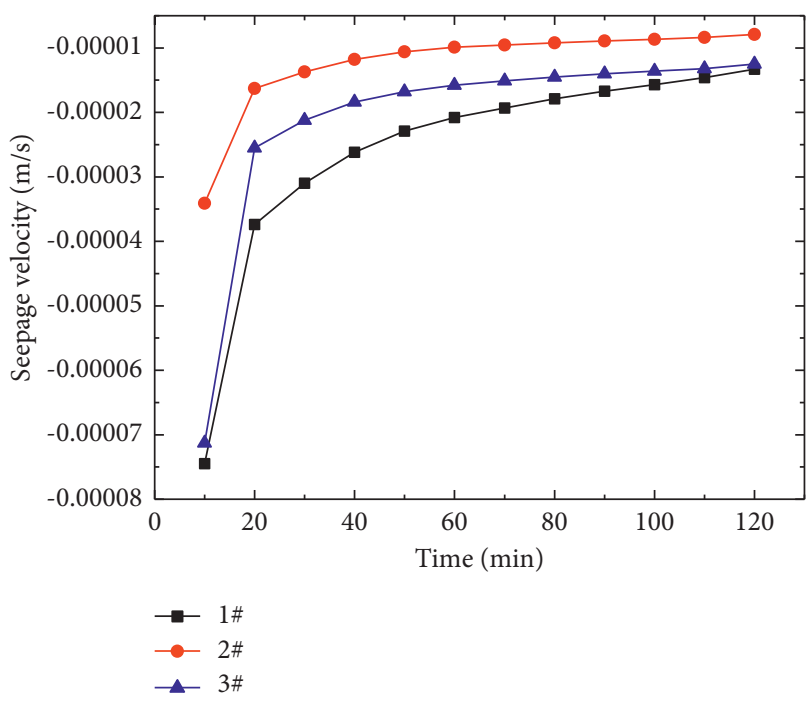

(b)

FIGURE 32: Infiltration velocity of observation points 1-3 of (a) buildings 1-2 and (b) buildings 2-4 with seepage wells placed around buildings 1 and 2 in the numerical model.

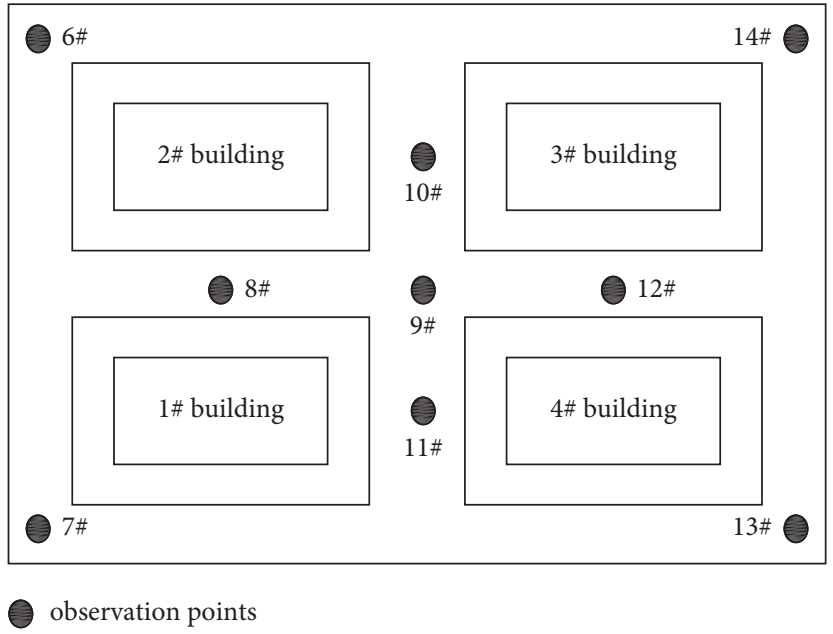

FIgURE 33: Observation points of buildings and pavements in the numerical model.

(2) Installation of Seepage Wells around Building 1. The changes in the pore water pressure over 120 min of rainfall at observation points 6-14 with seepage wells placed around building 1 are shown in Figure 35.

Figure 35 shows that the pore water pressures decrease at observation points 7,8 , and 11 , which are adjacent to the seepage wells of building 1 , compared with the case of no seepage wells. There are no obvious changes in the pore water pressures at other observation points. Because the seepage wells cause the rainfall around building 1 to infiltrate the ground, the infiltration of rainwater into the surrounding underground soil is reduced.

(3) Installation of Seepage Wells around Buildings 1 and 2. The changes in the pore water pressure over $120 \mathrm{~min}$ of rainfall at observation points 6-14 with seepage wells placed around buildings 1 and 2 are shown in Figure 36 .
Figure 36 shows that the pore water pressures decrease at observation points $6,7,8,10$, and 11 , which are adjacent to the seepage wells of buildings 1 and 2, compared with the case of no seepage wells. There are no obvious changes in the pore water pressures of other observation points. Compared with the case of seepage wells around building 1 only, the pore water pressure at observation point 8 exhibits obvious changes. This is because the seepage wells of buildings 1 and 2 influence this observation point.

(4) Installation of Seepage Wells around All Buildings. The changes in the pore water pressure over $120 \mathrm{~min}$ of rainfall at observation points $6-14$ with seepage wells placed around all buildings are shown in Figure 37.

Figure 37 shows that when all the buildings are equipped with seepage wells, the pore water pressure at symmetrical positions of the model is the same. The pore water pressure 


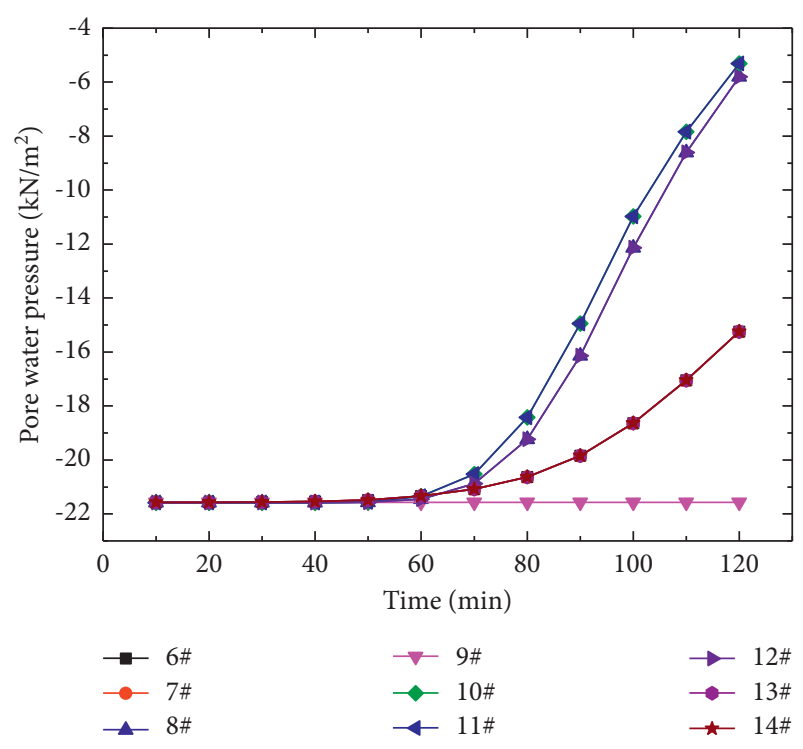

FIGURE 34: Pore water pressure of observation points 6-14 without any seepage wells in the numerical model.

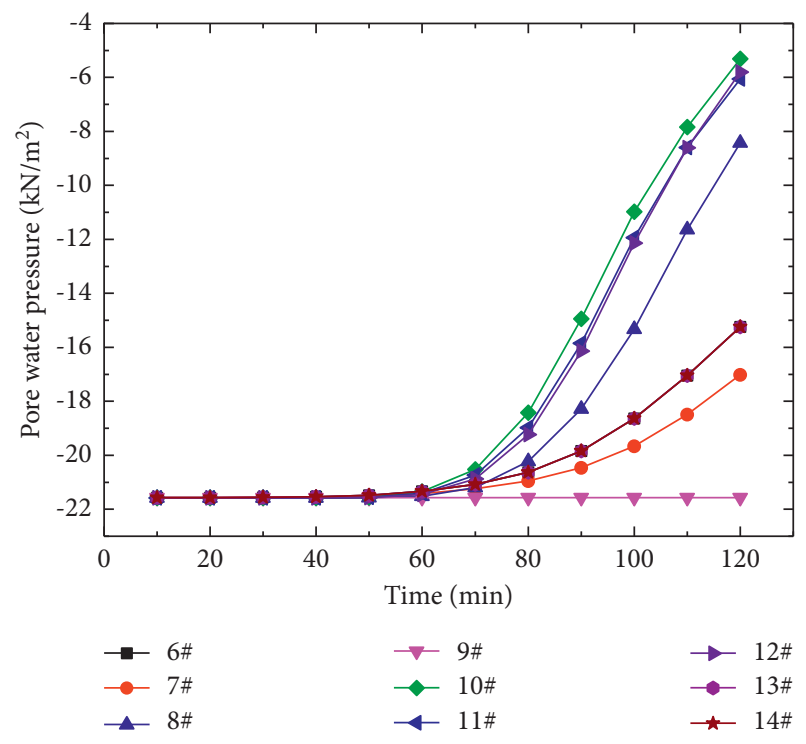

FIgURE 35: Pore water pressure of observation points 6-14 with seepage wells placed around building 1 in the numerical model.

at each observation point is lower than in the case without seepage wells. At observation points 10 and 11, located in the center of the four buildings, there is a larger change in the pore water pressure than when setting seepage wells were placed around buildings 1 and 2 . This is because the seepage wells of all buildings influence these observation points.

In summary, under the same working conditions, the difference in the pore water pressure at each observation point is not more than $0.010 \mathrm{kN} / \mathrm{m}^{2}$. When no seepage wells are included in the model, the pore water pressure at each observation point is about $-28.964 \mathrm{kN} / \mathrm{m}^{2}$ after rainfall for $10 \mathrm{~min}$ and $-26.598 \mathrm{kN} / \mathrm{m}^{2}$ after rainfall for $120 \mathrm{~min}$. Under the working conditions of a single building with seepage wells, two buildings with seepage

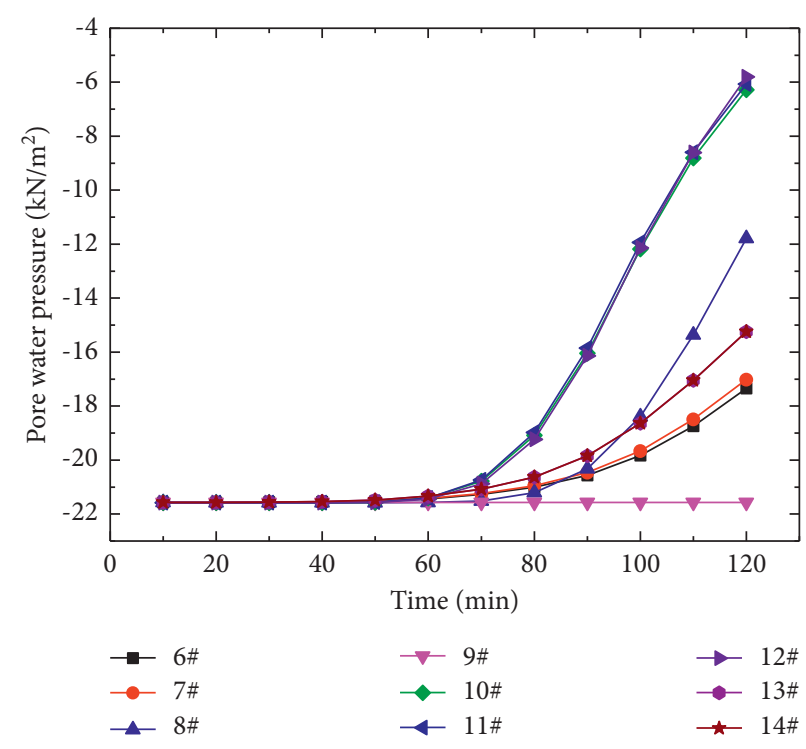

FIgURE 36: Pore water pressure of observation points 6-14 with seepage wells placed around buildings 1 and 2 in the numerical model.

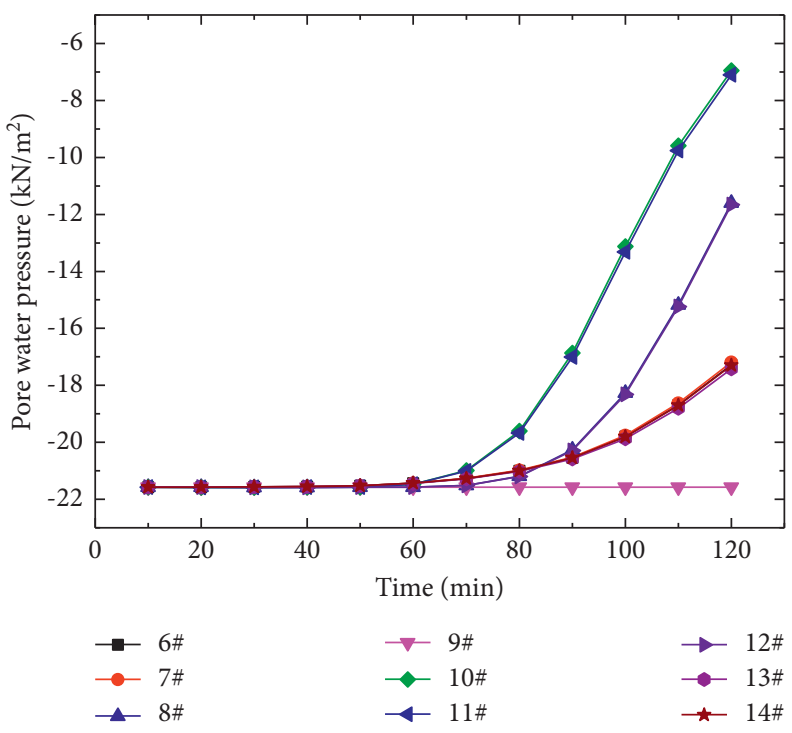

FIgURe 37: Pore water pressure of observation points 6-14 with seepage wells placed around buildings 1-4 in the numerical model.

wells, and all buildings with seepage wells, the pore water pressures around the buildings with seepage wells are similar, and the pore water pressure at each observation point is about $-28.638 \mathrm{kN} / \mathrm{m}^{2}$ after rainfall for $10 \mathrm{~min}$ and $-24.852 \mathrm{kN} / \mathrm{m}^{2}$ after rainfall for $120 \mathrm{~min}$. These results show that the seepage wells have little effect at the beginning of rainfall events. As the rainfall time increases, however, the influence of the seepage wells gradually increases because of the lateral infiltration of rainwater caused by the seepage wells. Overall, the impact area of the seepage wells is limited to about $1 \mathrm{~m}^{2}$, so it is recommended that all buildings be surrounded by seepage wells to alleviate urban waterlogging. 


\section{Conclusions}

This paper has described the development of concrete microseepage wells with good permeability and durability. The infiltration effect of concrete microseepage wells under different rainfall intensities has been studied through artificial simulated rainfall tests in situ. Numerical models of buildings and microseepage wells are verified by comparing the pore water pressure and infiltration velocity in the reference. Based on the verified numerical model, the influence of four kinds of seepage well arrangement schemes on the rainfall infiltration around buildings is analyzed, and the optimal arrangement is identified. The following conclusions can be drawn:

(1) The concrete microseepage wells are constructed using a mixture ratio of crushed stone, cement, and water of $1: 0.13: 0.11$. The optimum size of the crushed stone is found to be $0.5-1.0 \mathrm{~cm}$, and the optimum steel fiber content is found to be $2 \%$.

(2) Results of in-situ artificial simulated rainfall tests show that the infiltration of the concrete microseepage wells is greater under higher rainfall intensities. The water content at a given observation point decreases with increasing horizontal distance to seepage wells at the same depth and decreases with increasing depth at the same horizontal distance to seepage wells. Therefore, concrete microseepage wells can enhance soil infiltration performance.

(3) Compared with the case of no seepage wells, the pore water pressure, total head, and infiltration velocity obviously decrease at each observation point around a single building with seepage wells. As the rainfall time increases, the pore water pressure, total head, and infiltration velocity in each region decrease continuously. After $120 \mathrm{~min}$ of rainfall, the infiltration velocity at each observation point around all buildings becomes stable, and the infiltration velocities of observation points 1 and 3 are similar.

(4) When two buildings are surrounded by seepage wells, the pore water pressure nephograms, total head nephograms, and infiltration velocity nephograms all exhibit symmetric distributions, similar to the case of a single building with seepage wells. As the rainfall time increases, the pore water pressure, total head, and infiltration velocity gradually decrease and become stable after rainfall for $120 \mathrm{~min}$.

(5) Nine observation points are considered to analyze the influence range of the seepage wells. The results show that the pore water pressure, total head, and infiltration velocity are similar in the cases where one, two, and all buildings have seepage wells. At the beginning of the rainfall event, the seepage wells have little influence on the infiltration of the soil, but the influence increases over the duration of the rainfall. Considering that the influence area of the seepage wells is about $1 \mathrm{~m}^{2}$, it is recommended that all buildings should be equipped with seepage wells as the best method to alleviate urban water logging.

\section{Data Availability}

The data used to support the findings of this study are included within the article.

\section{Conflicts of Interest}

The authors declare that they have no known competing financial interests or personal relationships that could have appeared to influence the work reported in this paper.

\section{Acknowledgments}

The authors gratefully acknowledge financial support from the National Natural Science Foundation of China (No. 52108333), the Natural Science Foundation of Tianjin (Nos. 20JCQNJC01320, 18JCQNJC08300, and 18JCYBJC90800), the Natural Science Foundation of Jiangxi Province (No. 20202BABL204058), and the Major projects of the Science and Technology Department of Jiangxi Province (No. 20203ABC03B05).

\section{References}

[1] H. Chang, Y. Makido, and E. Foster, "Effects of land use change, wetland fragmentation, and best management practices on total suspended solids concentrations in an urbanizing Oregon watershed, USA," Journal of Environmental Management, vol. 282, no. 1, Article ID 111962, 2021.

[2] W. B. Cutter and A. Pusch, "The role of cost, scale, and property attributes in landowner choice of stormwater management option," Landscape and Urban Planning, vol. 209, Article ID 104040, 2021.

[3] M. Saadat Foomani and B. Malekmohammadi, "Site selection of sustainable urban drainage systems using fuzzy logic and multi-criteria decision-making," Water and Environment Journal, vol. 34, no. 4, pp. 584-599, 2020.

[4] M. Rodrigues and C. Antunes, "Best management practices for the transition to a water-sensitive city in the south of Portugal," Sustainability, vol. 13, no. 5, p. 2983, 2021.

[5] W. Chen, M. Zheng, Q. Gao, C. Deng, Y. Ma, and G. Ji, "Simulation of surface runoff control effect by permeable pavement," Water Science and Technology, vol. 83, no. 4, pp. 948-960, 2021.

[6] N. Bateni, S. H. Lai, F. J. Putuhena, D. Y. S. Mah, M. A. Mannan, and R. J. Chin, "Hydrological impact assessment on permeable road pavement with subsurface precast micro-detention pond," Water and Environment Journal, vol. 34, no. S1, pp. 960-969, 2020.

[7] J. L. Wang, Y. Q. Zhang, Q. C. Qin et al., "Water control of permeable pavement based on impermeable soil with perforated pipe," Science Technology and Engineering, vol. 18, no. 12, pp. 286-291, 2018.

[8] S. H. Xu, Y. H. Zhang, and B. F. Hong, "New design of gravel pile and vertical infiltration pipes on low impact development (LID) measures for aquifer recharge in a sponge city," Shanghai Land \& Resources, vol. 37, no. 2, pp. 70-74, 2016.

[9] X. Zhu, S. Q. Li, Y. F. Feng et al., "Study on application of rainwater seepage well in sponge city," Journal of Guangxi University, vol. 42, no. 4, pp. 1415-1421, 2017.

[10] Y. F. Feng, S. Q. Li, Z. X. Chen et al., "Experimental study and verification of rainwater infiltration well based on soil 
anisotropy," Journal of Yangtze River Scientific Research Institute, vol. 36, no. 3, pp. 114-119, 2019.

[11] Y. X. Liu, S. Q. Li, and T. X. Hu, "Application of sand and stone seepage wells in sponge city construction of clay area," Journal of Water Resources and Water Engineering, vol. 30, no. 3, pp. 113-118, 2019.

[12] M. Liang, M. X. Xue, and H. P. Feng, "Runoff regulation effect of new type seepage well and permeable grid measures," China Water \& Wastewater, vol. 36, no. 3, pp. 114-122, 2020.

[13] S. Prathipati and C. Rao, "A study on the uniaxial compressive behaviour of graded fiber reinforced concrete using glass fiber/steel fiber," Innovative Infrastructure Solutions, vol. 6, no. 2, pp. 1-14, 2021.

[14] H. Kasagani and C. Rao, "The influence of hybrid glass fibres addition on stress-strain behaviour of concrete," Cement Wapno Beton, vol. 21, no. 5, pp. 361-372, 2016.

[15] S. Yazici, G. Inan, and V. Tabak, "Effect of aspect ratio and volume fraction of steel fiber on the mechanical properties of SFRC," Construction and Building Materials, vol. 21, no. 6, pp. 1250-1253, 2007.

[16] X.-Z. Cui, "Dynamic numerical analysis of antimoisturedamage mechanism of permeable pavement base," International Journal of Geomechanics, vol. 10, no. 6, pp. 230-235, 2010.

[17] C. Liu and X. Zhang, "Numerical simulation of seasonal variations of base course resilient modulus in pavement structures in nonfrost regions," Journal of Transportation Engineering, Part B: Pavement, vol. 146, no. 3, Article ID 04020038, 2020.

[18] Q. H. Xu, C. W. Yu, J. L. Zhang et al., "The characteristic analysis of the short-duration rainstorm extremes in four cities of Hebei province based on the Chicago method," Torrential Rain and Disasters, vol. 37, no. 3, pp. 94-98, 2018.

[19] L. Chu, T. F. Fwa, and K. H. Tan, "Evaluation of wearing course mix designs on sound absorption improvement of porous asphalt pavement," Construction and Building Materials, vol. 141, pp. 402-409, 2017.

[20] B. B. Hu, J. Wang, S. Y. Xu et al., "Analysis on characteristics of precipitation change in Tianjin over the past 50 years," Journal of Arid Land Resources \& Environment, vol. 23, no. 8, pp. 71-74, 2009.

[21] J. Y. Hou, S. Q. Li, and Y. Y. Wang, "Analysis of water seepage performance of water seepage member suitable for sponge city construction," Journal of Liaoning University of Technology (Natural Science Edition), vol. 39, no. 5, pp. 323-325+350, 2019. 